\title{
FETICHES KONGO, MOMIAS ATACAMEÑAS Y SOBERANÍA COLONIAL. TRAYECTORIA DE GustaVo LE PAIGE S.J. (1903-1980)
}

\author{
Jorge Pavez Ojeda ${ }^{1}$
}

\section{* Introducción}

Resumen

Luego de varios años de misión en el Congo Belga, dedicado a la evangelización y a la etnografía, el sacerdote jesuita Gustavo Le Paige se instala en el oasis de San Pedro de Atacama, e inicia un plan de excavaciones arqueológicas que lo llevarán a desenterrar varios miles

de cuerpos de los cementerios indígenas atacameños. A partir del análisis de su archivo, mostraremos que detrás de este aparente giro disciplinario como efecto de su salto transatlántico (de la etnología a la arqueología, de África a América), encontramos una cierta continuidad de interés en una materialidad fetichizada como vestigio de culturas en "desaparición". Tanto en el Congo como en Atacama, Le Paige se volvió un agente de resignificación de los objetos, transformando su valor de culto (fetiches de las religiones congo o nkissi, cuerpos momificados y ajuares de los "abuelos" atacameños) en valor de exhibición para las colecciones museísticas de sociedades "civilizadas".

Palabras claves: museos y colecciones - historia de la antropología colonialismo - Kwango - Atacama.

\begin{abstract}
After several years of mission on the Belgium Congo, spending time on evagelization and ethnography, the Jesuit priest Gustavo Le Paige take place in the oasis of San Pedro de Atacama (North of Chile), and begins a plan of arqueologics excavations that will take him to excavate several thousands corpses of the Atacameños cementeries. From the analysis of his archive, I will show that behind this apparent disciplinary turn as an effect of his Atlantic jump (from ethnology to arqueology, from Africa to America), we find some continuity of interest in a fetishisized materiality as remains of "disapearing" cultures. In the Congo as in Atacama, Le Paige became an agent of resignification of the objects, transforming their cult value (fetishs from Congo or nkissi religion,

mumified bodies and grave goods of the Atacama's "abuelos") in exhibition value for the museistics collections of "civilised" societies.
\end{abstract}

Key words: Museums and collections - History of Anthropology Colonialism - Kwango - Atacama
Más allá de la biografía, el estudio de la trayectoria religiosa, política e intelectual del sacerdote jesuita belga Gustavo Le Paige permite abordar los problemas relacionados con tres líneas de investigación que hemos emprendido hace un tiempo. El estudio del "colonialismo republicano", como expresión específica de los procesos de conquista, ocupación y colonización de territorios indígenas por parte de las formaciones estatales republicanas (siglos XIX y XX), permite aproximarse a las lógicas coloniales propias de los Estados criollos, cuestionando la historiografía tradicional que da por concluidos los procesos de colonización con las "independencias" americanas. Las ideologías y prácticas coloniales de las repúblicas se encarnan en archivos y biografías que dan cuenta de sus íntimas relaciones ideológicas con otras formas históricas de colonialismo (Menard y Pavez 2007; Pavez 2008; Menard 2010; Foerster 2011; Foerster y Vezu, 2011). En este caso, veremos como se expresan formas pre-republicanas de colonización de territorios indígenas $y$, alternativamente, se reproducen formas monárquicas imperiales (andinas u occidentales) en una época de proyectos descolonizadores. El estudio de la relación del padre Le Paige con la historia y la prehistoria atacameña también permite entender los vínculos entre el colonialismo republicano con el "indigenismo militar", forma ideológica del colonialismo integrador practicado por varias dictaduras en América Latina, la que no solo considera enfoques de integragión geopolítica de territorios indígenas como parte de una Doctrina de Seguridad Nacional, sino también una particular lectura raciológica

Recibido: noviembre 2011. Aceptado: marzo 2012.

${ }^{1}$ Instituto de Investigaciones Arqueológicas y Museo, Universidad Católica del Norte. Gustavo Le Paige 380, San Pedro de Atacama, CHILE. Email: jpavez@ucn.cl 
de la historia nacional que busca raíces indígenas para una mitología nacionalista (Palacios 1904; Téllez 1944; Vidal 1989; Muzzoppapa 2003). Finalmente, el caso Le Paige también permite contribuir al desarrollo de una historia de la antropología que atienda a las formas mercantiles y políticas del intercambio y a las formas de subordinación política y sociocultural que permitieron la producción de saberes hegemónicos sobre las sociedades colonizadas, lo que hemos desarrollado como estudio del "gabinete etnológico" y de su lugar en "la derrota del área cultural". Como herramienta heurística, la noción de "derrota del área cultural" permite avanzar en la crítica histórica y antropológica del culturalismo que ha priorizado la supuesta particularidad y anterioridad histórica de las "áreas culturales" por sobre el análisis de las formas de su producción y disolución como efecto de los procesos coloniales mismos (Pavez 2003, 2005, 2007, 2009; Menard 2006; Vezub 2006, 2009; Menard y Pavez 2011). Los procesos cripto-coloniales en Atacama en el siglo XX parecen ofrecer un interesante caso de estudio para afirmar la necesidad de hacer explícitas las formas en que se desplegaron el colonialismo republicano y el indigenismo militar en este territorio.

\section{* La soberanía del misionero}

Recientemente se ha publicado en Bélgica valona un libro cuyo título puede resultar impúdico o escandaloso. Se trata de la biografía que Christian du Brulle (2010) le dedica a Gustavo Le Paige, fundador del museo que lleva su nombre en San Pedro de Atacama. Le dernier roi de l'Atacama es sin duda un título discutible, que viene a proponer una visión del personaje despojada de los pudores políticos republicanos, indigenistas e indígenas. Más aún, plantea en el centro de su preocupación el rol político del misionero, es decir, la cuestión de la soberanía en Atacama, cuestión política más que científica o religiosa, a las cuales está en este caso estrechamente ligada. La soberanía se enuncia aquí en tonos monárquicos desde Bélgica, un país donde el reportaje en tierras salvajes tiene una sólida tradición colonial. El misionero Le Paige es presentado alternativamente como "jefe del pueblo", "gerente general", e "indiscutiblemente, el último rey de Atacama" (De Brulle 2010). Biografía sensacionalista y superficial en muchos aspectos, El último rey de Atacama sorprende con la entrega de varios documentos que per- miten conocer aspectos poco discutidos de la trayectoria de Le Paige, no abordados por la Cronología de un misionero de Lautaro Núñez (1993), obra esta última que se puede inscribir en la tradición disciplinaria de lealtad a la figura fundadora (Fabiani 2005). Más específicamente, El último rey aborda con precisión dos episodios poco documentados de la vida de Le Paige: su paso y salida del Congo Belga por orden del Vaticano, y su activismo pinochetista desde el golpe de Estado de 1973. Intentaremos entonces precisar estos dos momentos políticos de Gustavo Le Paige, estableciendo su coherencia con dimensiones más "abstractas" (espirituales, científicas, ideológicas) de su pensamiento y actividad intelectual y productiva. Esto nos permitirá abordar una interrogante mayor, propiamente científica y disciplinaria, respecto al tránsito de la actividad investigativa de Le Paige, desde sus intereses sobre el arte religioso kongo del complejo nkissi en el Kwango, hasta sus excavaciones de cementerios y tumbas de los "abuelos" atacameños para su exhibición museológica como cuerpos humanos "deshidratados" en el desierto de Atacama.

En esta discusión del caso Le Paige está en juego la problemática foucaultiana de los paradigmas del poder, especialmente la oposición que elabora Foucault entre una mecánica jurídica del poder soberano, y una mecánica del poder basada en dispositivos disciplinarios. En esta oposición, la "edad clásica" funda la soberanía en el carácter binario de una guerra de razas, donde el poder se concibe como un bien - una riqueza- que se intercambia y se acumula, y el sujeto se constituye como un súbdito del poder. Sin embargo, en el siglo XVIII habría aparecido una "nueva mecánica del poder", que "recae sobre los cuerpos y lo que hacen más que sobre la tierra y sus productos", y que aplica su vigilancia y sus coerciones materiales para generar una economía que incrementa las fuerzas sometidas y las fuerzas que someten (Foucault 2000: 31-37). De esta manera, esta mecánica del poder se opone a la vieja forma soberana, aquella que desplaza y se apropia de la riqueza y los bienes, y transmite un orden jurídico de obligaciones y cánones. Mientras que la teoría soberana piensa el poder absoluto como gasto absoluto, la teoría disciplinaria del poder va a pensar la economía de gastos y la máximización de la eficacia. Para Foucault, ambas formas del poder, la del "derecho de la soberanía (ley)" y la de la "mecánica de la disciplina (normalización, ciencias humanas)" serían profundamente incompatibles 
(Foucault 2000: 43-45). Sin embargo, esta tesis no se sostiene frente al caso Le Paige, aunque ayuda a discutir el carácter del poder ejercido por el misionero, como sacerdote, científico y soberano local, atendiendo a la "fabricación de los sujetos más que la génesis del soberano", y a "las técnicas [del poder], su heterogeneidad y sus efectos de sometimiento", entendiendo el modelo disciplinario como articulador de "operadores de dominación" (Foucault 2000: 50-51). Gustavo Le Paige proviene de una tradición colonial monárquica, imperial y africanista, que sin embargo se adaptará sospechosamente bien al colonialismo republicano chileno. Esta tradición imperial se ejerce como forma soberana de la política, el sujeto y la ley, y supone ciertas diferencias con el poder de las disciplinas chilenas (científicas, territoriales, corporativas), en formación en los territorios del norte desde la Guerra del Pacífico. Sin embargo, el caso Le Paige muestra precisamente un proceso de inversión, donde la tradición monárquica imperial instala los dispositivos disciplinarios y la modernidad colonial republicana se expresa en la forma de un antiguo orden soberano. Las disciplinas no habían aún conquistado Atacama en la forma que lo hace Le Paige, quien logra entregar los territorios atacameños a todas las posibilidades de producción de plusvalía disciplinaria (a la economía de los saberes y sus objetos) y esto por medio de la heterogeneidad de la soberanía en la historia política, social y económica. Tendremos así que enfrentar la paradoja de un soberano misionero que gestiona una economía del poder a partir de mecanismos disciplinarios, alimentándose de la captura y ordenamiento de cuerpos, fuerzas, objetos y territorios atacameños, volviéndose así un hombre clave de la soberanía colonial nacional en tiempos del régimen militar. Entonces empecemos por el principio.

\section{* Fetiches kongo, arte Cristiano y EVANGELIZACión COLONIAL DE África}

En 1928, con 25 años, el seminarista Gustavo Le Paige hace su primer viaje al Congo Belga, asignado a la misión de Wombali. Tres años después, vuelve a la metrópolis a causa de la muerte de su madre. Inicia entonces sus estudios de teología con John Janssens s.j., futuro superior general de la Compañía, ocasión en que conoce al seminarista chileno Alberto Hurtado, a quien acompaña en su ordenación sacerdotal. Una vez ordenado sacerdote,
Le Paige vuelve al Congo como misionero itinerante de la Misión de Yasa (1934). Al año de misión, escribe un artículo programático sobre el arte africano indígena (Le Paige 1935), en el cual propone una visión etnológica del arte como herramienta para la evangelización. Ahí señala que el estudio del arte indígena puede ayudar a conocer el parentesco entre las "razas" y las relaciones entre los habitantes de diferentes provincias, lo que permitiría encontrar las relaciones de "dependencia religiosa" entre las razas, por ejemplo a través del préstamo e intercambio de "estatuillas-fetiche" entre grupos étnicos, tema de relevancia para los misioneros y los étnologos de las religiones africanas. ${ }^{2}$ En la misma época, M. Colas s.j. adelanta a partir de una suma de evidencias etnográficas que la mayor parte de los fetiches en el Congo son fabricados por "razas extranjeras e importados: el envolver lo desconocido de su misterio solo les confiere más eficacia" (Colas 1938: 100), estableciendo así un principio relevante del sistema de prestaciones religiosas entre los grupos que fueron poblando el Congo. Le Paige llama a reconocer el "genio de nuestras razas congolosas y evitar destruirlo", y propone "al contrario fomentarlo y dirigirlo y no imponer nuestras artes europeas", lo que tampoco deberá significar oponerse a la civilización cristiana y "favorecer una vuelta al paganismo". Para salvar el arte negro, concluye Le Paige, "hay que dirigirlo y sobre todo orientarlo hacia el cristianismo". De esta manera, el misionero se impone sobre el etnólogo, y la estrategia evangelizadora se despliega con cierto grado de ingenuidad etnográfica y una buena dosis de pragmatismo. Ingenuidad, al sugerir el estudio de las diferencias en las representaciones escultóricas antropomorfas de mujeres y hombres, como forma de conocer mejor la religión tradicional kongo, cuando el antropomorfismo escultórico ya era, al menos desde 1910, un efecto de la preferencia y los encargos de los administradores y coleccionistas coloniales (Jewsiewicki 1991: 316). Pragmatismo, al promover la sustitución de un tipo de escultura por otra, como en el ejemplo que celebra, sobre un misionero que le dijo a un escultor que le "fabricara estatuillas que representen un boy, tamboreros, un leopardo, etc." y se los compraría, ante lo cual el indígena volvió con muchas esculturas.

\footnotetext{
2 Como ejemplo, Le Paige describe el caso de Masamba, mensajero del jefe muboma, que atravesaba el Kwango a pie para consultar el fetichero Bayaka del sur y traer el fetiche que le permitiría contrarrestar un maleficio (Le Paige 1935: 248)
} 
En los años siguientes, Le Paige desarrollará la correspondencia más relevante que tuvo como misionero etnógrafo, con Joseph Maes, el sabio del Museo de Tervuren, quien desde su gabinete coordinaba las investigaciones etnológicas belgas en el Congo, y ordenaba los objetos que le enviaban misioneros y funcionarios coloniales. En las cartas que se intercambian entre los años 37 y 39 , Maes le trasmite algunas de las ideas que defiende desde hace varias décadas en el Museo Real. En relación a la obtención de objetos justamente, señala que se podían comprar objetos pero nunca mandarlos a fabricar por encargo (Coutennier 2004: 434, 464-465 y 472), al contrario de lo que el mismo Le Paige promovía para "orientar" y "dirigir" el arte africano. Maes también insistía en la recolección de información etnográfica para los objetos. Con esa información, y lo que recogió en una importante expedición al Congo (penetrando entre 1913 y 1914 los distritos del Lago Leopoldo II y de Kasai), Maes desarrollaba clasificaciones de fetiches, figurinas, apoya-cabezas y mapas étnicos (Shuylenberg 1995; Coutennier 2004). Cuando entra en correspondencia con Le Paige, el estudio de los tambores estaba, como le señala el director etnográfico al director del museo, "sur le métier". ${ }^{3}$ Esto explica la insistencia de Maes para que Le Paige le enviara detalles de "viejos tambores y viejos tam tam con figuras humanas y animales" y "figurines funerarios" que se encontraran en las tumbas de "notables y jefes". ${ }^{4}$ Le Paige le enviará a Maes respuesta detallada con el dibujo de tres tambores, quitándoles valor por no ser "trabajados": "ni manos esculpidas, ni mangos, ni dibujo de ornamentación: un tronco de árbol vulgarmente tallado y ahoyado (creusé)". Esta "pobreza" la explica por ser la región visitada "el punto de encuentro de la emigración de tres razas, Bayansi, Bambala, (y Bahugana) y Bagongo"; y concluye que "enviarle uno de esos tambores no le servirá de nada y no podrían figurar nunca en ninguna colección". ${ }^{5}$ Maes le señala que está en un "profundo error" y que los tambores dibujados son de extrema relevancia, insistiendo en que Le Paige se procure los tambores y que estos sean

\footnotetext{
3 Jefe de sección [J. Maes] al Director del Museo, Tervuren, 8/02/1938. Dossier 1008, Archive de la Section Ethnographique, Musée Royale d'Afrique Centrale. La correspondencia citada en lo que sigue proviene toda de este dossier. Agradezco a Julien Volper por haberme facilitado su acceso.

4 J. Maes a G. Le Paige, Tervuren, 27/10/1937; J. Maes a G. Le Paige, Tervuren, 7/02/1938.

5 G. Le Paige a J. Maes, Yasa, 15/07/1938.
}

viejos y usados. ${ }^{6}$ También le envía documentación científica y le pide las fotografías que pueda realizar, para tener así "nueva documentación". Luego, le solicita "orientar sus investigaciones" hacia las estatuillas y figurinas de "estilización animal o humana" sin dejar de insistir que "acepte solo las piezas na kala kala". Pero el primer interés de Le Paige no era especialmente etnográfico, por lo que insistió en encargar piezas a los escultores, para "dirigir" el arte africano hacia el "arte cristiano". Mientras Maes promovía la producción de un archivo de la cultura material africana existente, Le Paige como agente evangelizador hacía oficio de impulsor y transformador del arte, para que los artistas africanos produjeran las imágenes y objetos de un nuevo culto civilizador. La guerra interrumpirá este diálogo entre Maes y Le Paige, e imposibilitará el envío de los tambores. En 1948, después de un viaje de Le Paige por Lisboa, Bruselas y Roma, O. Boone, el sucesor de Maes en el Museo de Tervuren, vuelve a insistirle sobre los tambores Bayanzi, y aprovecha de pedirle un mapa a gran escala de las regiones misioneras de Yasa y Ngi. $^{8}$

Unos años antes, Le Paige ya había terminado su obra magna de etnografía sobre estas regiones del país Kwango (Le Paige 1944). Un volumen de más de 600 folios, destinado a documentar el problema de las migraciones históricas en la cuenca del Congo (el "éxodo" muchas veces forzado que caracteriza la historia bantú, por las presiones esclavistas sobre las costas hasta bien avanzado el siglo XIX) y sus consecuencias para la propiedad y herencia de tierras, y para la sucesión de las jefaturas tribales. La obra incluye visitas a pueblos, censos, análisis de abundante cartografía y estudio de los objetos símbolos de autoridad, y apoya la tesis de una movilidad generalizada de grupos que, en las últimas tres generaciones, se han trasladado de tierras instalándose más cerca de otros grupos, apropiándose de la tierra y estableciendo un sistema general de intercambio religioso. Este trabajo estaba destinado a contribuir al debate eclesiástico sobre

\footnotetext{
6 J. Maes a G. Le Paige, Tervuren, 30/09/1938.

7 J. Maes a G. Le Paige, Tervuren, 8/02/1939. Maes era un antidifusionista, y se oponía a las teorías de Frobenius, sobre el contacto del arte, lengua y civilización bantú con civilizaciones lejanas de Egipto (van Shuylenberg 1995: 27). Sus investigaciones buscaban probar la particularidad del hogar civilizatorio del Congo como origen de una raza, cultura y "alma negra".

8

O. Boone a G. Le Paige, Tervuren, 11/02/1948.
} 


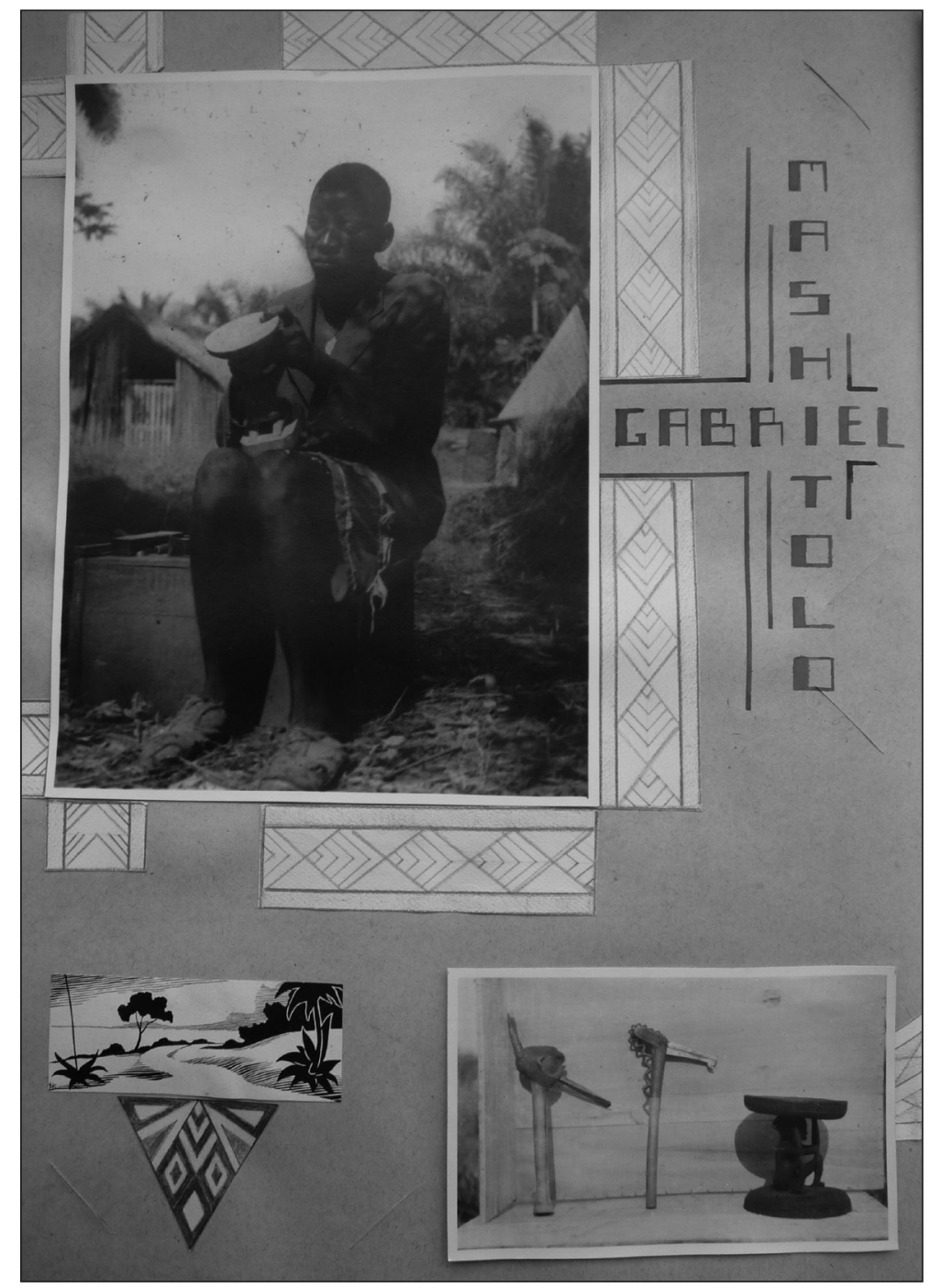

Figura 1. Gabriel Mashitolo tallando. Álbum de arte y arquitectura cristiana, por G. Le Paige. Archivo IIAM-UCN.

el problema que significaban las constantes migraciones de los grupos del Congo para el éxito de la evangelización (Houben 1929). De ahí también el valor de la información etnográfica sobre los objetos que solicitaba Maes, que permitiría reconstruir el sentido y las lógicas de estas migraciones históricas y de los contactos entre los diferentes grupos bantú. Para Le Paige, el problema específico parece ser la dificultad de encontrar estilos artísticos definidos que pudieran ser recuperados para el "arte cristiano", condición aurática de la evangelización exitosa, que los misioneros llamaron "aculturación cristiana” (CEE 1968: 131 y CEE 1969: 82-86).
Desde su correspondencia con Maes, y en oposición a este, Le Paige otorga gran importancia estratégica a las obras por encargo: el encargo de obras permitía introducir ideas del arte como expresión de símbolos cristianos. El mismo año en que termina su etnografía, Le Paige escribe sobre el escultor batshok Gabriel Mashitolo, quien encarna el ideal de evolución artística a la que aspiraba diez años antes para el arte cristiano indígena, realizado por un artista évolué proveniente de un grupo con una importante tradición de máscaras y estatuillas (Figura 1). Mashitolo trabajó primero solo en la Misión de Kahemba, ensayando la escultura de retablos, crucifijos y relieves, 


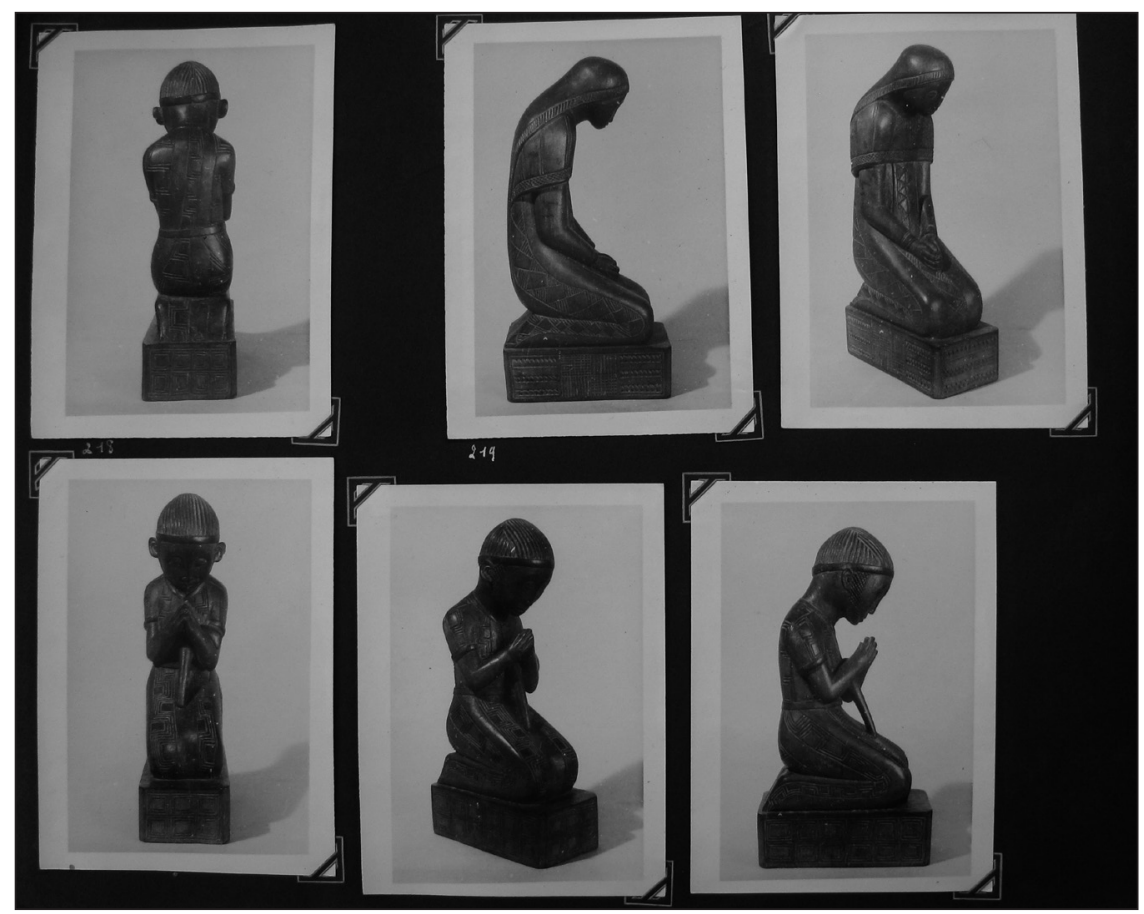

Figura 2. Piezas 208 a 2015. Arte cristiano africano, por Gabriel Mashitolo. Álbum fotográfico intitulado Collection Ethnographique et Artistique déposée au Musée du Congo à Tervuren par le R. Père G. Le Paige s.j. (1948). Archivo del Centro Multimedia. Biblioteca Central de la Universidad Católica del Norte.

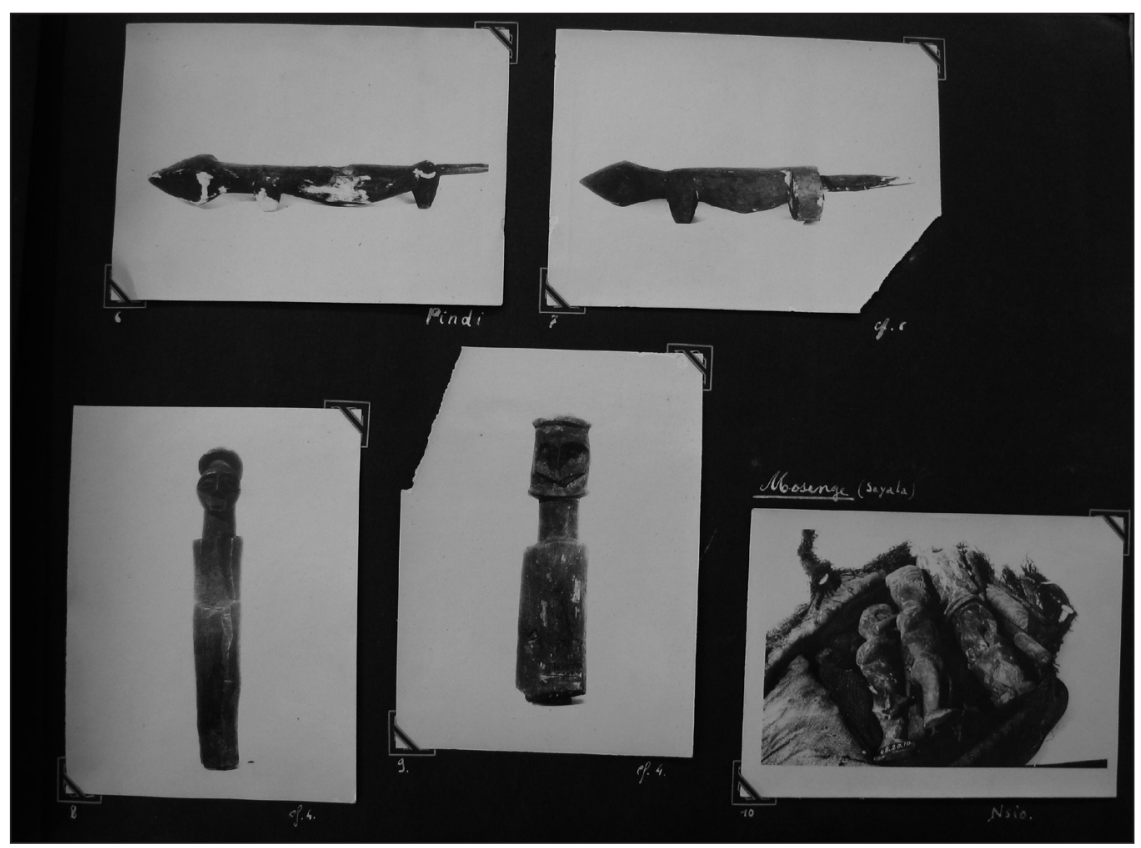

Figura 3. Figurines Teba. Álbum fotográfico intitulado Collection Ethnographique et Artistique déposée au Musée du Congo à Tervuren par le R. Père G. Le Paige s.j. (1948). Archivo del Centro Multimedia. Biblioteca Central de la Universidad Católica del Norte. 


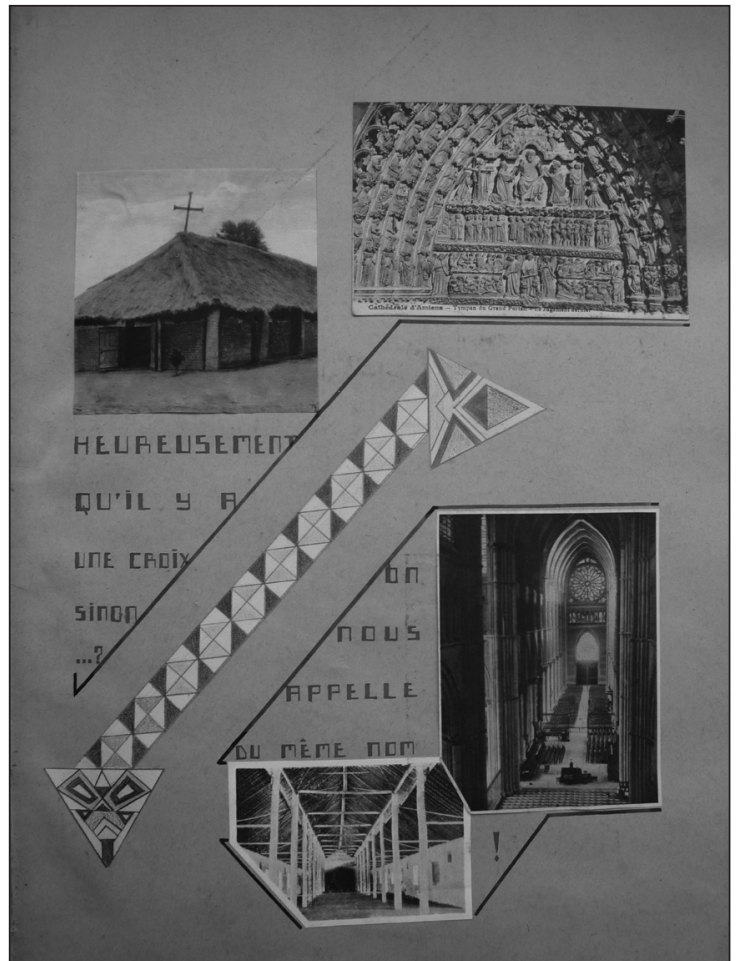

Figura 4. "Heureusement qu'il y a une croix sinon...? / On nous appelle du même nom”. Álbum de arte cristiano, por G. Le Paige. Archivo IIAM.

hasta terminar dirigiendo un taller creado por Le Paige en la misión, donde enseña arte cristiano a sus discípulos (Figura 2). Los misioneros venían fomentando desde los años 20 los talleres de esculturas (en Rungu) y cooperativas de artistas (en Buta) pero especialmente con el fin de reproducir "curiosidades" de la "verdadera Africa" (Jewsiewicky 1991: 321) y no orientado a un "arte indígena cristiano" como el que se practicó en el taller de Mashitolo en Yasa. En la publicación del texto de Le Paige quedará afuera el capítulo dedicado a su valoración del arte batshok y su apreciación de la "evolución" del escultor Mashitolo, de quien destacará el "dinamismo capaz de renovar el arte religioso" entre los pueblos del Kwango (Le Paige, 1949: 451). En 1948, Le Paige había enviado una Collection etnographique et artistique de obras del Kwango al Museo de Tervuren, colección en la cual se contaban varias obras de Gabriel Mashitolo y sus alumnos. ${ }^{9}$ El álbum fotográfico

9 Según las fichas de las esculturas de Gabriel Mashitolo que se encuentran en el MRAC, "después de la partida del P. Le Paige, que documenta esta colección de 239 piezas, tiene una narrativa clara de la evolución deseada - del arte "pagano" al arte cristiano- y contribuye a entender la idea civilizadora de Le Paige. Mientras que el sacerdote parece satisfecho de los logros de su método de evangelización del arte y con las producciones escultóricas de la escuela Mashitolo, el artículo de 1948 se explaya con más inquietud sobre la importancia de la transformación de la arquitectura para producir los soportes espaciales donde exhibir ese arte, por ejemplo la arquitectura religiosa de capillas. Le Paige señala que en África ésta no puede inspirarse de la arquitectura civil, ya que no hay entre los artistas africanos "arquitectos constructores", como hay herreros, escultores y pintores. Pero como estas "artes menores" requieren "soporte arquitectónico", se vuelve un problema crear una atmósfera que inspire respeto y recogimiento en las masas reunidas en días de fiesta, las que le dejaban la impresión negativa de una "gran feria" (Le Paige 1949: 448). De esta misma época puede datarse el álbum iconográfico que crea Le Paige para ilustrar los contrastes y posibilidades evolutivas del arte cristiano europeo al africano indígena. En este álbum, notablemente cargado a la iconografía arquitectónica, parece haber una resignación ante la imposibilidad del monumento en África, compensada por la facilidad de una evolución de las que llama "artes menores" (Figura 2, 3 y 4). Le Paige también toma posición respecto al problema de la "racialización" de la pintura de la Virgen y el Cristo, señalando que solo cuando la raza blanca ya no sea la civilizadora, cuando los negros se encuentren entre las "razas civilizadas" y tengan su propio clero, recién ahí, liberados de tener que representar el ideal superior en la forma de un blanco, será necesario pintar a Cristo, la Virgen y los ángeles como negros africanos "con sus propios rasgos" (Le Paige 1949: 449-450). ${ }^{10}$ Desde esta perspectiva, resulta significativo que al momento de su salida forzada del Congo, el mismo Le Paige pinte el cuadro de un Cristo negro, inspirado en la gran desesperanza producida por esa decisión de sus superiores.

Mashitolo dejó la misión y se estableció como escultor independiente, buscando exclusivamente la clientela europea". Cfr. Ficha de Inventario 4820220, "Berger de la crèche", 2/06/1948, Archive Section Ethnographique, MRAC.

${ }^{10}$ El argumento es típico de la administración colonial europea, pero también de todo evolucionismo civilizatorio, como el del brasilero Gilberto Freyre, quien en 1974 aún pensaba que los mozambicanos no estaban preparados para liberarse de Portugal y autogobernarse. 


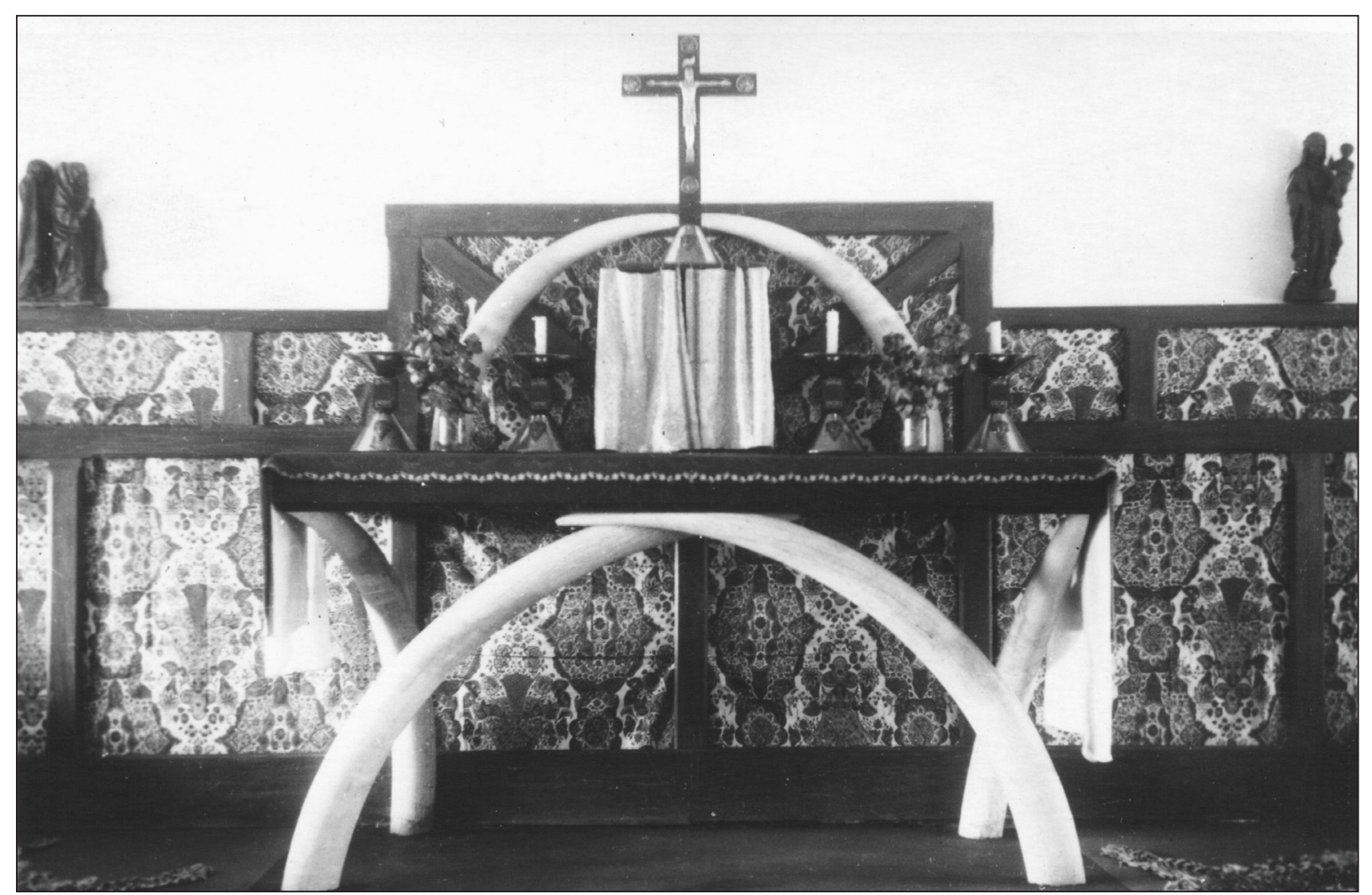

Figura 5. Altar cristiano africano. Archivo IIAM.

Al mismo tiempo, Le Paige se plantea el problema del estatus de los objetos de culto africanos, actualizando la antigua controversia jesuita sobre las incompatibilidades de los objetos y cultos "paganos" y cristianos, debate conocido desde el siglo XVI como la "controversia de los ritos chinos". En esta discusión, Le Paige practicaba la tradición jesuita de Mateo Ricci, como consta en el relato del rito de investidura de un jefe cuya sacramentación le permitía al sacerdote afirmar la eficacia de la evangelización sacramental por la fórmula "ex opere operandis" (Foerster 1996), es decir, validada por la presencia sacerdotal:"

"Sobre la mesa que debía servir al sacrificio de la misa, depositaba las insignias de jefe que me presentaban los notables: el collar de dientes de leopardo rodeaba el pie del cálice, las pulseras de

\footnotetext{
${ }^{11}$ Esta fórmula siguió predominando al menos hasta la década del setenta en el Congo, como atestiguan los debates "etnopastorales" publicados por el Centre d'Etudes Ethnologiques de Bandundu, donde uno de los presentes resalta: "hay que estar presente en las ceremonias [africanas], luego dejarán transformar y orientar a la fe cristiana" (CEE 1969: 81-82).
}

brazo al lado. Ofrecía el Sacrificio explicándole a todos que este era el único que actualmente servía. Antes de dar la comunión a mis cristianos, pasaba el collar alrededor del cuello del nuevo jefe con la ayuda de los notables y le ponía sus pulseras en el brazo izquierdo, haciendo participar la mayor cantidad posible de paganos en el único Sacrificio redemptor tan necesario para ellos como para nosotros. Bajo el altar del Sacrificio, los indígenas habian puesto sus arcos, flechas, viejos rifles, lanzas, machetes, hasta sus perros de caza, y luego se partía a la caza hasta el amanecer" (Le Paige, en Du Brulle 2010: 40).

De esta manera, el mismo rito de investidura antes desarrollado en la tumba del jefe muerto, sobre la cual se hacían ofrendas de animales, se trasladó al espacio sacramental delimitado por el cura cristiano, quien garantiza que, desde ese momento, los jefes paganos esperaran su paso por la aldea para hacer estas ceremonias. Estos jefes a su vez le tributaban con regalos, como pieles de leopardo y cuernos de elefantes, con los cuales el misionero decoraba las capillas (Núñez 1993: 19; Du Brulle 2010: 37; ver también Figura 5). Sin embargo, el sacerdote también 


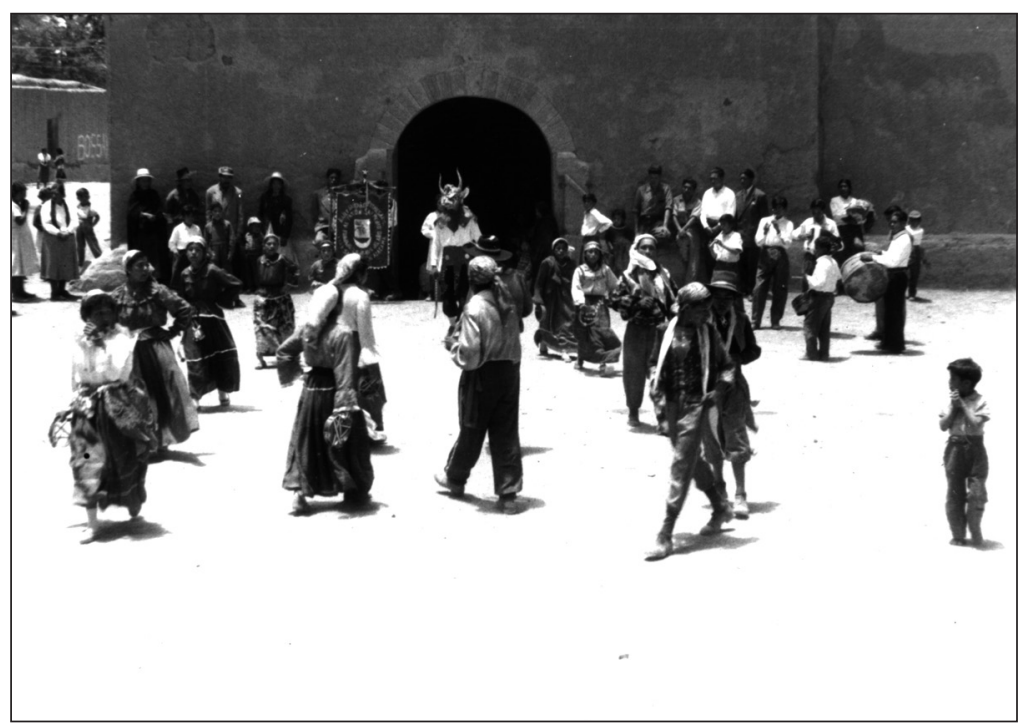

Figura 6. Baile gitano, con un diablo enmascarado a la entrada de la iglesia.

controlaba y censuraba otros símbolos, como los amuletos y talismanes que pedía dejar fuera de la iglesia (Núñez 1993: 21; Leopoldo III, en Du Brulle 2010: 37), la música de los tambores que le parecían "cacofónica" y los bailes que consideraba "inmorales". Años después, residiendo en San Pedro de Atacama, Le Paige hace una revisión de su etapa congolesa, explicitando su estrategia de evangelización. Señala que para cristianizar "hay que conocerlos a fondo [a los indígenas] y no europeanizarlos", y habla concretamente de dos áreas de conocimiento -el "estudio etnográfico profundo" y el "estudio del arte"y un área de acción: la adaptación de todo esto a la vida cristiana "persiguiendo lo que era inmoral (bailes) para conservar lo más posible sus costumbres" (Le Paige, en Du Brulle 2010: 38-39).

En Atacama, repetirá los métodos y la prioridad evangelizadora, aunque se cambiará a las disciplinas arqueológica y antropométricas. De hecho, la experiencia en el Kwango lo llevará a adoptar ciertas previsiones (por ejemplo, en relación a la evangelización de poblaciones migrantes y la dificultad de establecer los hogares de origen de sus expresiones religiosas), que lo llevarán a restringir los bailes religiosos atacameños a cada uno de los pueblos, condenando que los bailes de un pueblo visitaran o se practicaran en otros pueblos. Así también, exigirá el retiro de las máscaras cuando estos bailes entraban en procesión a las iglesias de la diócesis (Figura 6), ${ }^{12}$ y prohibirá la entrada a las iglesias de la "cuartada": "El cuarto se refería a la cuarta parte de un animal faenado, de una llama. Los danzantes se colgaban el cuarto por el cuello sujetándolo con ambas manos y así daban brincos y pasos por el interior de la iglesia. Esta danza de mal gusto la prohibió Le Paige en todas las iglesias de su diócesis" (Melcher 2004: 125).

A pesar del pudor y convencionalismo de Le Paige, su defensa estratégica de las "costumbres indígenas" será motivo de una enconada disputa con el obispo Guffens de Kinzambi (Kwango). Según el mismo Le Paige,

"El resultado fue una investigación general en el Kwango por un visitante designado por Roma. Duró más de siete meses y en consecuencia Roma exigió la renuncia de mis dos superiores eclesiástico y religioso y me pidió de ir ayudar al padre Hurtado a Chile, ya que mi puesto de misión, Ngi, había sido otorgado a la Congregación del Verbo Divino, todo esto para camuflar el hecho que un caporal que tiene razón en contra de su coronel debe cambiar de regimiento!" (Le Paige, en De Brulle 2010: 36). ${ }^{13}$

\footnotetext{
${ }^{12}$ Com. pers. Cristina Garrido.

13 Sobre el episodio, ver también la carta de Mifundu Zacharie a Le Paige, Kinshasa, 14/02/1968. Archivo IIAM.
} 


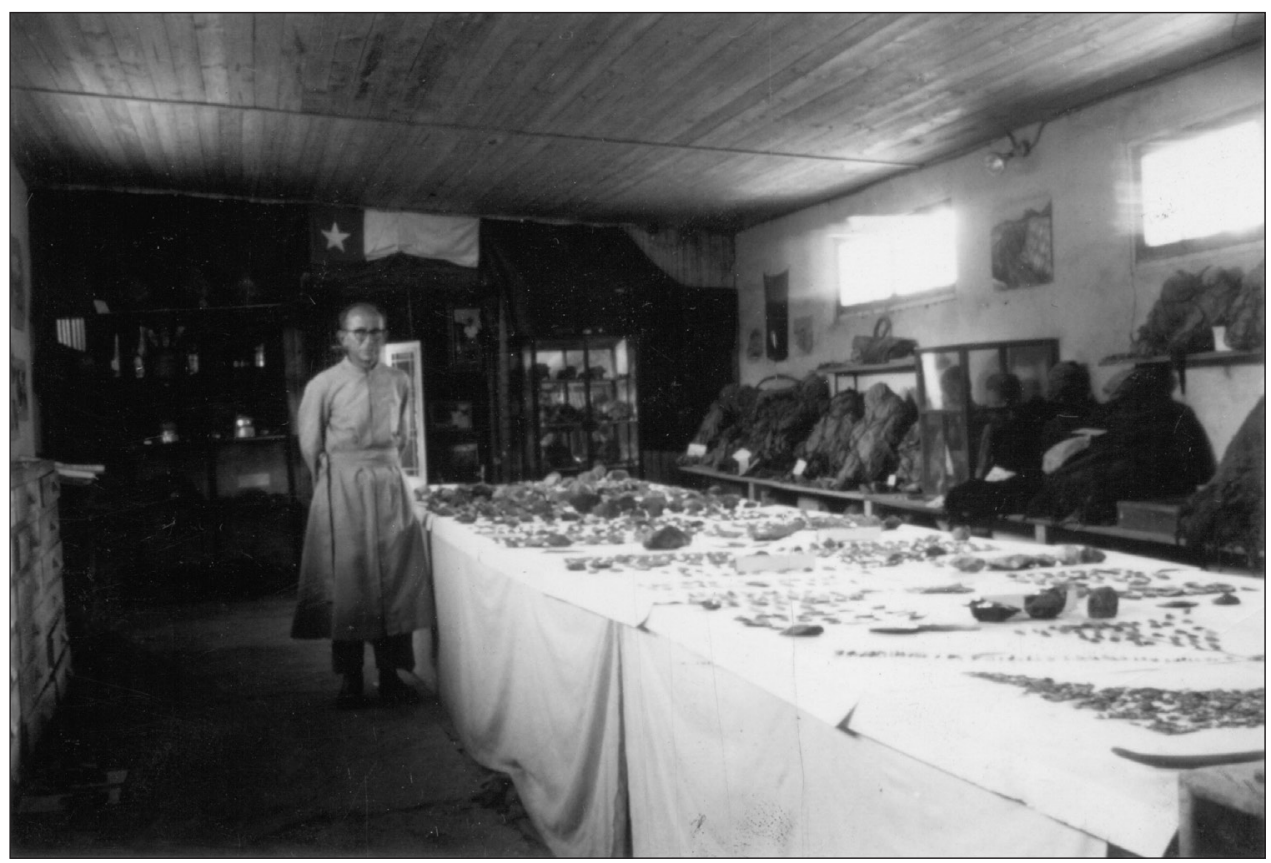

Figura 7. G. Le Paige en el Museo de la casa parroquial, 18 de julio de 1960.

A los 47 años Le Paige dejaba el Congo para nunca volver. El superior Janssens acepta enviarlo a Chile, donde el misionero jesuita tenía intenciones de trabajar con Alberto Hurtado. ${ }^{14}$ Pero, como escribe Le Paige, "el P. Alberto Hurtado había muerto el 18 de agosto (1952) sin que lo sepamos, o mejor sin que me avisen haciendo creer que me mandaban a Chile para ayudarlo!!?". Designado en Chuquicamata, en febrero del 54, escribirá sobre esta experiencia "mi peor año, el único de mi vida"; lo que se puede explicar por sus problemas con el otro párroco del campamento de Chuqui, y la hostilidad de un medio obrero sindical y una clase patronal protestante.

\section{^ Poder, magia y tabú: la excavación de cementerios atacameños}

Cuando descubre San Pedro de Atacama, Le Paige pide rápidamente su traslado a esa parroquia (marzo del 55). A partir de entonces empezará a recorrer toda la región.

\footnotetext{
${ }^{14}$ En esos años, Alberto Hurtado había publicado varios textos sobre la carencia de vocaciones sacerdotales para el catolicismo chileno (Hurtado, 1936 y 1941).
}

El mismo contó varias veces sus inicios en la arqueología: "Un día estaba pintando en pleno desierto, porque siempre me ha gustado mucho la pintura, cuando noté algo que sobresalía de la tierra. Escarbé como un loco y di con una tumba con dos cuerpos". ${ }^{15}$ La pintura, que había sido una importante dedicación en el Congo, pasará a segundo plano. Sin embargo, el cambio de motivos pictóricos es sintomático de su progresivo desinterés en la representación (artística y etnográfica) de sujetos vivos. Mientras que en el Congo pintaba personajes políticos, niños y escenas de la vida aldeana, en Atacama pintará algunos pocos paisajes y croquis vaciados de sus habitantes. ${ }^{16} \mathrm{En}$

${ }^{15}$ Revista Vea, "El Padre Le Paige muestra en Santiago sus hallazgos iniciados por "Chiripazo'", 14/08/1969; ver también El Mercurio de Santiago, "Tumbas de los primeros habitantes de Chile", por Raquel Cordero, 5/11/1961.

${ }^{16}$ Estas pinturas, catalogadas como "ingenuas" o "naives", serán expuestas en varias oportunidades. En 1974, en Santiago y Antofagasta, en una exhibición organizada por la galería de Enricco Bucci, y honrada por la visita del general Pinochet; en el 75 de nuevo en Santiago, justo antes de recibir el doctorado honoris causa de la Universidad del Norte; y en una retrospectiva que hará gira por Arica, Iquique y Antofagasta poco antes de su muerte, la cual consta de doce cuadros, diez hechos en el Congo y dos en 
cambio, desde su primer hallazgo, Le Paige no dejará de excavar el desierto.

A fines de 1955, ya tiene censados 145 cuerpos humanos, y se convence de haber descubierto vestigios "paleolíticos". También empieza a negociar sus "descubrimientos", invitando a representantes de la Universidad del Norte a conocer sus terrenos. Sin embargo, se lamenta de no haber sido tomado en serio: "La U vino a hacer su shopping" de piezas arqueológicas, comenta en su diario, al verlos adquirir lo que llama "una momia falsa" (Du Brulle zoro: 6o). Dos años después, Le Paige inaugura un Museo en la Casa parroquial (Figura 7), desentierra el "cuerpo deshidratado" de quien se volverá un ícono de su trabajo -la famosa Miss Chile-, y filma una película sobre sus excavaciones de momias, representantes de lo que llama la "alta civilización atacameña" (siglos IX al XI). ${ }^{17}$ En los años siguientes, acrecentará su fama de "descubridor" con hallazgos destacados, como los ocho cementerios en fila en el río San Pedro, con alfarería de los siglos IXXIII, la cerámica La Candelaria del siglo III y los "queros" de oro tiwanakotas del siglo VIII en Larache (1958), las tres capas sobrepuestas de tumbas en Solor (1960), las diferentes y cuantiosas series tipológicas de tabletas de rapé (1961), todo lo cual va confirmando la necesidad de "un gran museo arqueológico". ${ }^{18} \mathrm{Al}$ año siguiente, Le Paige recibe la visita del arqueólogo Alex Krieger, quien apoya su tesis de los 40.000 a 25.000 años de antigüedad para la ocupación humana de Gatchi, y confirma que un cráneo de la colección Le Paige formaría parte de una "raza más antigua que la de Lagoa Santa". ${ }^{19}$ En los años sesenta siguen los hallazgos, por ejemplo entre Calama

Atacama. El Mercurio de Calama, "Padre Le Paige presentará una exposición", 20/01/1979.

${ }^{17}$ La película, dirigida por Pedro Rosso, se proyectó en San Pedro de Atacama, Calama, Chuquicamata y Bélgica. Entre 1957 y 1962, la verán miles de personas, solicitando incluso su repetición en las salas. Esta película muda costó 4 mil dólares de la época, y gran parte de ella estaba dedicada al desentierro de momias (Du Brulle 2010: 111-114). La cinta original fue encontrada hace poco en el Museo Arqueológico de San Pedro (2009), pero según últimas noticias, desapareció del museo.

${ }^{18}$ El Mercurio (Santiago), "Tumbas de los primeros habitantes de Chile", por Raquel Cordero, 5/11/1961.

${ }^{19}$ El Mercurio (Santiago), "Un sacerdote al servicio de la ciencia", 29/04/1962. El reportaje señala la excavación de 164 tumbas y 371 sepultados, e incluye ilustraciones (un mapa de cementerios antiguos, fotos de un cráneo de Quitor y de líticos de Gatchi). y Antofagasta "dos lugares o hábitat del paleolítico inferior", los que llevan a Le Paige a concluir que "la zona fue totalmente diferente con valles, lagunas y también poblados con animales prehistóricos". ${ }^{20}$ Por las interpretaciones que propone desde sus primeros hallazgos, se puede considerar al sacerdote como el "impulsor principal del nuevo round del debate" sobre el paleolítico en Chile (Erhart 1998: 116; Le Paige 1963), el cual se inició en las primeras décadas del siglo XX a partir de las investigaciones de Max Uhle, Augusto Capdeville y Ricardo Latcham, y su aplicación de las tipologías del comparatismo lítico promovido por Uhle (1922). Le Paige insistirá en esta proyección tipo-cronológica del evolucionismo unilinear europeo a la prehistoria americana, en lo cual será apoyado por el mencionado Krieger (y su concepto de "Pre-proyectil Point", 1964), Edward Lanning (y su concepto de "Biface Tradition", 1970), Mario Orellana y Bernardo Berdichewsky, a pesar de las tempranas y repetidas críticas de Junius Bird (en 1943 y 1965) al tipologismo sin control estratigráfico y al paralelismo con las secuencias líticas europeas que proponían Latcham y Krieger (Erhardt 1998; Trigger 1989). Con la introducción de los conceptos secuenciales de "paleoindio" y "arcaico" (temprano, medio y tardío), se darán por terminadas las especulaciones sobre el paleolítico en Chile (Núñez 1980, 1983). ${ }^{21}$

Casi 20 años después de la llegada de Le Paige a San Pedro, la Guía del Museo Arqueológico señala la existencia de 300 sitios arqueológicos identificados, 4.885 tumbas excavadas de las cuales se obtuvieron 378 momias com-

${ }^{20}$ El Norte (Antofagasta), "Sensacional hallazgo de Le Paige", 31 de marzo 1967, incluye foto de Le Paige junto a una momia. La presentación científica de sus hallazgos se puede encontrar en Le Paige 1957-58, 1961, 1964, 1965, 1966, 1973, 1974a, b, c, 1975a, b, 1976 a, b, c, y 1977 .

${ }^{21}$ Luego de su visita a los yacimientos excavados por Augusto Capdeville en Taltal, Uhle (1916) plantea dudas sobre la interpretación que se le puede dar a los materiales del conchal. Sin embargo, estas dudas son pasadas por alto por Ricardo Latcham, Aureliano Oyarzún y Capdeville (Mostny 1964), ya que el mismo Uhle insistirá posteriormente en su inicial error comparativo (Uhle 1922; Erhardt 1998: 109-115). Le Paige (1975a) hablará de "sitios paleolíticos" apoyándose en la autoridad fundacional de Uhle, para difundir la idea de una ocupación humana masiva y de faenamiento de megafauna extinta a partir de la interpretación de lugares que eran simplemente, en la terminología de Uhle, "sitios cantera-taller" (Erhardt 1998: 116). 
pletas, y alrededor de 5.000 cráneos (Le Paige 1974a). ${ }^{22}$ Hacia el final de su vida, Le Paige cuenta como fue acumulando momias atacameñas: "La gente quería que fuera a sus casas a sacar 'espíritus que penaban'. Entonces descubrí que los lugareños enterraban sus cadáveres muy cerca de sus residencias". ${ }^{23}$ Manuel Abán, uno de los primeros ayudantes de Le Paige, entrevistado en 1969 por El Mercurio de Calama, confirma esta versión, pero menciona también a los "abuelos" como propagadores del miedo y la brujería, implícitamente opuestos a las excavaciones. Dice Abán:

"Al principio tenía un poco de miedo. Después el 'padre' nos ha enseñado a no tener miedo. Además las momias no hacen nada. [Entrevistador: ¿La gente del pueblo los ayuda?] Sí. Cuando descubren alguna cosa corren a avisarnos. Lo que pasa es que tienen mucho miedo a los espiritus de las momias. Siempre nos avisan cuando descubren entierros en sus casas o cuando trabajan en el campo. Nosotros vamos y les sacamos los muertos. [E.: iPor qué ellos les temen a las momias?] Por los abuelos de nosotros. Ellos, los más viejos siempre cuentan historias de brujerías. Dicen que los muertos no hay que tocarlos porque hacen males y hacen que todo salga mal en las cosas que uno hace". 24

Es evidente que toda "la gente" no valora de la misma manera los "descubrimientos" de Le Paige cerca de sus residencias. Algunos le informaban al sacerdote del emplazamiento de los cementerios antiguos o de la aparición de tumbas en sus casas; otros no estaban de acuerdo pero no se oponían públicamente, generando así un silencio cómplice. Hay que complementar la valoración universitaria de las excavaciones de Le Paige (Núñez, 1993; Orellana 1996; Hubbe et al. 2011), con algunas visiones

\footnotetext{
${ }^{22}$ Una reseña actual de esta colección osteológica de las más importantes del mundo, establece que la mitad de la colección se encuentra hoy en regular o mal estado de conservación, es decir, inapta para estudios científicos. Entre los materiales en mal estado, están gran parte de los restos provenientes del sitio llamado Solor 3, donde fue encontrada la momia llamada Miss Chile y que constituye el conjunto de restos más antiguos datados al radiocarbono (siglo I-IV DC) (Hubbe et al. 2011).

23 "Yo no llamaría momias a los cadáveres que hemos descubierto. Mas bien se trata de cuerpos deshidratados, porque la arena del desierto provocó la descomposición acuosa". El Mercurio (Santiago), "Cerca de su museo, Le Paige espera terminar sus días", 18/02/1979.

${ }^{24}$ El Mercurio de Calama, "Atacameño excava tumbas indígenas desde los 11 años", 5/12/1969.
}

locales, las que no solo se muestran críticas de los métodos con los cuales el misionero arqueólogo se apropia de los restos humanos, sino que también revelan el lugar heterogéneo que ocupa este personaje en el imaginario atacameño sobre la muerte. Le Paige es acusado de faltar el respeto a las tradiciones fúnebres, específicamente, de romper con la prohibición social (tabú) de entrar en contacto con los cuerpos de "abuelos", "antiguos" o "gentiles", y peor aún, de desenterrar estos cuerpos de los cementerios llamados gentilares o chullperíos (en quechua).

Según los testimonios recogidos por los arqueólogos Ulises Cárdenas (2001: 8-10) y Patricia Ayala (2008: 103-106), la compulsión del sacerdote por desenterrar muertos de los cementerios antiguos habría generado "indignación" en los habitantes de San Pedro y una sensación de "engaño". Sin embargo, se dice que nadie se opuso públicamente, por tratarse de las actividades de una "autoridad", que no le rendía cuenta a nadie y por lo tanto, "hacía lo que quería... [el padre Le Paige] hizo lo que quiso, pero sin consultar ni la opinión de las comunidades". La ausencia de oposición explícita a las actividades del sacerdote también se asocia al miedo que habrían sentido los atacameños, y que una dirigenta actual reconoce como una debilidad que ha costado superar: "hemos sido un tanto sumisos, callados, no planteamos las cosas oportunamente...". ${ }^{25} \mathrm{Al}$ leer con detención las "percepciones" de los atacameños (Cárdenas 2001), podemos ver que el miedo al sacerdote proviene de otro miedo anterior, que se despliega por efecto de contacto y que justifica el tabú aplicado a los restos mortuorios de los "gentiles". El miedo que describen los entrevistados de Cárdenas vincula el museo, los muertos y el sacerdote, como un mismo conjunto de fuerzas oscuras, heterogéneas e ingobernables, a las que hay que respetar, temer y/o evitar. Respecto al museo por ejemplo, un habitante de la localidad de Toconao señala que:

"para mí [el museo] es malo... las personas de aquí del lugar tienen respeto... hay mucha gente que no va por eso, yo he escuchado a personas adultas al entrar al museo, no quieren entrar porque tienen miedo... les da lástima, como están, quizás abuelos de sus abuelos, sienten ese tipo de miedo, respeto... yo siempre cuando he

\footnotetext{
${ }^{25}$ Intervención de Mirta Solís, presidenta de la comunidad de Catarpe. Reunión de participación ciudadana, Proyecto Nuevo $\mathrm{Mu}$ seo, diciembre de 2010.
} 
entrado al museo de San Pedro no me ha dado gana de mirarle a la gente [momias] que esta ahí, cierto, porque es una lástima" (en Cárdenas 2001: 10).

Una agricultora de Río Grande por su parte señaló:

"no quise dentrar al museo de San Pedro porque ahí dicen que hay esqueletos de las personas de los abuelos... yo les tengo respeto... uno se puede enfermar igual que los niños... mi mamá me enseñaba ese respeto cuando éramos niños nos decía que no debíamos llorar por ahí porque los abuelos miran... porque por ahí hay casitas de los abuelos... y si se enfermaban se tenían que hacer convidos, los pagos... a todos los abuelos, con quinoa, aloja, vino" (en Cárdenas, 2001: 9).

La enfermedad y la muerte aparecen rápidamente en el discurso atacameño como los mayores males a los que se exponen aquellos que rompen el tabú de contacto, y se acercan a los restos de los "abuelos". En este punto, varios testimonios coinciden: a pesar de su poder, Le Paige no se salvó de la venganza de los "abuelos", y esto porque no le "pagó" a la tierra por extraer de ella los huesos. Para una pastora de Talabre, los gentiles "se comieron" a Le Paige, dejándolo a él en los huesos:

"La tradición que yo sé es que cuando uno saca algo debajo de la tierra tiene que darle un pago a la Pachamama, su comida, su licor, vino... y resulta que él [Le Paige] no lo hacía con todas las personas o donde iba a excavar... por eso a Le Paige lo mataron los gentiles... ese sí que ha excavao... ese ese excavaaaba... ese le comieron... porque dicen que le comen y le dejan bien flaco... se lo comieron los gentiles" (en Cárdenas 2001: 8).

Otro atacameño, de San Pedro, también señala las "profanaciones" de Le Paige como principal causa de su muerte:

"una viejita la Antonia Tejerina dijo 'por qué no le hacimos remedio de esa parte de los abuelos', entonces hablaron con él, pero fracasó, que no, 'Uhhh', [el padre] no creía en los abuelos... y de eso murió... a los poquitos días lo llevaron, allá duró como quince días en el hospital de la compañia [...] el cura los profanó [a los 'abuelos', mandaba a profanar y eso también no está muy bien, todos esos muchachos ahora ya están viejos, ya andan enfermos, achacosos andan por ahi". ${ }^{26}$

${ }^{26}$ Entrevista a Manuel Corante, por Hans Gundermann, 1998.
Manuel Corante se refiere aquí a los jóvenes que Le Paige llevaba a trabajar con él, en contra de las prevenciones de los mayores y los "compositores" (componedores de huesos) como Norberto Vilca, que prevenía a los niños de "no jugar con los abuelos", cuando uno de estos se enfermaba por haber encontrado un cráneo y jugado "a la pelota" con él (Corante y González 2008). Corante insiste al respecto: "estos antiguos son de mucho respeto... eso lo debió haber llevado a la tumba al curita, por ser quien profanó, ahí el patio de la casa parroquial, ahí se amontonaban los cráneos, parece un depósito de melones, si... lleno de cráneos, grandes y chicos", que Le Paige recogía en bolsas que después cargaban los niños. En el imaginario de los ancianos atacameños, el mismo destino parece estar reservado a todos los que trafican con restos mortuorios, excavando cementerios antiguos y comerciando los objetos. Una anciana de Toconao cuenta el caso de una joven mujer atacameña que habría muerto por las mismas causas morales y con los mismos males que Le Paige:

"una niña... ella sacaba... sacaba abuelos... abuelos, o sea que estaban completos tenían de todas cosas... tenían oro, plata todo eso, greda también... y ella sacaba a veces y vendía, y para mí que esos le comieron porque ella nunca pagó... ella era de acá y joven... ella vendía las cosas de valor... plata, oro... porque dice que antes, antiguamente los viejitos morían pero con todas sus cosas que ellos tenían... esa niña cuando se enfermó no le encontraron nada, nada y después se murio" (en Cárdenas 2001: 15).

No deja de ser significativo que las museógrafas del Museo de Madrid que manipularon las momias enviadas para la exposición de 1976, también se hallan enfermado por el contacto con estos cuerpos. ${ }^{27}$ Se trata de una evidencia más de la toxicidad química de estos restos humanos, de la cual los atacameños se han protegido culturalmente en base a la prohibición de contacto. Ya en 1964, por invitación del mismo Le Paige, el doctor Raul Etcheberry se lleva "trocitos de momias" y "156 muestras de sangre" para el análisis de laboratorio. Los resultados que obtiene muestran importantes cantidades de componentes tóxicos en los vestigios, recomendando el uso de mayores protecciones que las que empleaba el sacerdote. ${ }^{28}$

\footnotetext{
${ }^{27}$ Com. pers. Carmen Cerezo, conservadora del Museo de América (Madrid), mayo de 2010.

${ }^{28}$ R. Etcheverry B. a G. Le Paige, Santiago, 13/08/1964. Archivo IIAM-UCN.
} 
El imaginario "mágico-religioso de los Atacamas" (Mostny 1968) está poblado de muertos con los cuales conviven los vivos, delimitando claramente sus espacios físicos y alimentando vínculos con ellos en diferentes y determinados momentos, a través de varias prácticas rituales, funerarias, de fertilidad, de agradecimiento y "pago" de ofrendas. Existen diferentes maneras de entender las concepciones religiosas y las relaciones entre vivos y muertos en Atacama, especialmente el problema de su ordenamiento en el tiempo y el espacio. Las categorías de "abuelos" y "antiguos" refieren a veces indistintamente al conjunto de los muertos y almas, otras veces a tipos especiales de muertos. A su vez, los "gentiles" son "antiguos" que habitan lugares oscuros, marginales o alejados, los llamados "gentilares" o chullpas, que son cementerios antiguos (prehispánicos), lugares que se evitan y cuyos habitantes gentiles son objeto de tabú y prohibición de contacto. Estos "gentiles" también se expresan como supay animando los llamados "retratos de las peñas", es decir, las pinturas rupestres en quebradas y cuevas (Morales 1997; Castro 2009). Otros "antiguos" o "abuelos", en cambio, son los cerros (mallku), los manantiales, los rayos, las estrellas, las "animas benditas", que son diferentes tipos de entidades propiciadoras de vida con las cuales se mantiene comunicación ritual en tiempos y espacios normados por "las costumbres" (Castro 2009: 370-373; Martínez 1983 para "los dioses de los cerros"). Desde la etnohistoria se ha planteado que la categoría de "gentiles" alude a una forma de humanidad anterior a las conquistas imperiales (inka primero, hispano-criolla después). Esta humanidad habría vivido en una época de oscuridad, anterior a la aparición del Sol (personificado en el Inka o Reinka, aunque a consecuencia de la conquista y evangelización hispana, el mismo Inka fue resignificado como "gentil"), y se habría escondido a morir en trojas y cuevas cuando ocurrió esta forma de diluvio invertido, la desertificación por incandescencia solar (Castro 2009: 248-252, 262-263 y 381-382, quien trabaja también a partir de etnografía realizada en 1979; Ayala 2008; Martínez 2010). Otra lectura, basada en la reconstitución etnográfica de las concepciones religiosas atacameñas, ha planteado que las categorías de muertos no se ordenan cronológicamente en el tiempo histórico (en forma de sucesivas "generaciones") sino que se "comprimen" en un tiempo de tipo heterocrónico, en el que muertos y vivos conviven repartiéndose el espacio físico y el tiempo astral (el día, la noche, las temporadas, y las transiciones entre estos). En esta concepción heterocrónica o de una diacronía comprimida, que surge de la "gente de la tierra" (es decir de agricultores atacameños), el mito de la aparición del Sol no explicaría un evento histórico como la dominación del Inka o la evangelización colonial, sino la aparición del sol cada día al amanecer, cuando se esconden los gentiles y emergen los "dioses de los cerros" (com. pers. Cristina Garrido, 2012). ${ }^{29}$ El problema que enfrentan estas interpretaciones es el de la relación de filiación entre los "abuelos" (las diferentes generaciones de "antiguos" o "gentiles") y los actuales atacameños. La idea de filiación directa, es decir, la concepción de los "antiguos" como "antepasados" (también "anteabuelos"), implica una concepción diacrónica del tiempo donde se supone que los mitos explican los eventos y cambios históricos impuestos por diferentes olas de colonización (inka, española, chilena). Este vínculo histórico-filiativo fue promovido con fuerza por el mismo Le Paige, y hoy permea tanto en el discurso político de los dirigentes atacameños como en algunos intentos etnográficos (Ayala 2008). El discurso de filiación (los "antiguos" como antepasados de los actuales lican-antai) es inseparable de una estrategia patrimonial que tiende a la reapropiación autóctona de la cultura material acopiada por los arqueólogos, especialmente por Le Paige. Sin embargo, este discurso establece un sentido cronológico unilinear del tiempo que no corresponde al conocido dualismo andino, dualismo que parece también expresarse en la dicotomía abuelosgentiles/abuelos-no-gentiles como formas opuestas y complementarias de humanidad (día/noche, sol/luna, subsole/subterra, vivos/muertos, alto/bajo, nómades/ sedentarios, etc.). Estas dicotomías y las concepciones del tiempo que le subyacen pueden incluso ofrecer explicaciones de los eventos históricos de los procesos de colonización, sin por eso reconstituir una linealidad cronológica de filiación y descendencia (Salomon 2001).30

\footnotetext{
${ }^{29}$ Incluso, hoy en día en San Pedro de Atacama se concibe que una persona pueda haber sido "gentil" cuando era un niño pastor (es decir, no "domesticado" por la civilización agrícola), antes de su transformación en vida en un adulto cristiano evangélico. Agradezco especialmente a la antropóloga Cristina Garrido haberme comunicado estos resultados de su prolongada etnografía en los ayllus atacameños.

30 Suponiendo que la categoría de "gentil" y el temor a estos "abuelos" fue "producto de la acción cristiana" de extirpación de idolatrías, Ayala (2008: 104-105) señala que Le Paige habría "negado una creencia impuesta por su propia religión durante la Colonia",
} 
Las teorías africanistas del fetichismo permiten entrever los alcances políticos de la interacción de un sacerdote arqueólogo con los muertos "antiguos" (gentiles), en una comunidad que se ha mantenido alejada de ellos por medio de un tabú de contacto. En este caso, los conceptos africanos nos permitirán pensar en los problemas de la "corporeidad" y los límites de las "apariencias objetivamente necesarias" (Palmié 2006) en la región atacameña. Los estudios de la magia en África destacan que la frontera entre las cosas y los humanos es borrosa y ambigua, lo que podría analogarse a la relación andina entre los "gentiles" y los "dioses del cerro" (Martínez 1983): "los humanos existen bajo dos formas, como personas vivas y como osamentas muertas, como agentes en acto y como reliquias de agentes difuntos"; de esta manera, la distancia con las cosas se perturba: "si los humanos son también cosas, por qué las cosas, y en primer lugar aquellas que tienen estatus de artefactos humanos, no serían personas" (Bazin, 2008: 539). La relación de Le Paige con los muertos atacameños, su proyecto de museo para reunir restos mortuorios personificados, recuerda la relación del brujo kongo -el nganga- con el fetiche que "contiene los muertos" -el nkisi-, cuyo momento decisivo de fabricación es la inclusión de tierra proveniente de una tumba o de los restos de un difunto. Como reveló Lidia Cabrera, "el brujo toma control sobre un 'muerto' apropiándose de sus huesos" (cit. en Palmié 2002: 173), atrayendo al espíritu que quiere salir de su tumba hacia los restos de su antiguo cuerpo. El nkisi se vuelve así "una especie de tumba portátil en la cual un espíritu personal venido del mundo de los muertos se hace presente [y...] se incorpora al fetiche algunos restos físicos de sus 'operadores' sucesivos, volviéndose así el condensado de las generaciones de nganga que lo han servido" (Bazin 2008: 540). En el paso de África a América - del Congo a Cuba-, el nombre del sacerdote dueño del nkisi-el

abriendo paso a la restitución de la filiación de atacameños como descendientes de los antepasados "gentiles". Sin embargo, esta concepción patrimonialista de la filiación elimina la posibilidad de entender estas categorías como marcadores de la inmanencia entre un antes y un después, una civilización y otra, un espacio y otro, lo material y lo inmaterial, es decir, como forma de concebir la discontinuidad y la heterocronia del tiempo, opuesta a la continuidad cronológica linear promovida tanto por la ciencia occidental como por la religión cristiana, conjunción que encuentra en el paleontólogo Teillard de Chardin, maestro de Le Paige, su expresión más acabada. nganga- pasa a significar el nkisi, el objeto fetiche mismo, como si por efecto del traslado, el sacerdote africano se volviera él mismo un fetiche, como si el dueño africano se objetivara en la cosa afrocubana, pasando el sacerdote a llamarse "tata nganga". La operación mágica sin embargo se repite. El sacerdote "va a establecer contacto con el espíritu de un ser humano muerto e instalarlo ritualmente en un contenedor -el objeto nganga-" (Palmié 2002: 167), algo parecido a un museo conteniendo muchas momias. Stephan Palmié subraya que la relación entre el espíritu y su contraparte humana "es descrita a menudo como un pacto o acuerdo registrado y rodeado por símbolos de trabajo asalariado y pago, dominancia y subalternidad, esclavización y revuelta", mientras que el "padre de la nganga (tata nganga)" es concebido como un "empresario místico que manda una fuerza de trabajo atada por contrato o captura" (Palmié 2002: 167-168). La contratación o captura de un nfumbi (muerto) supone establecer posesión sobre "substancias conectadas metonímicamente con la personalidad de un humano fallecido". Las ngangas (y los muertos que contiene) son "alimentadas después de la realización de una tarea específica. Trabajan a comisión, y en la medida que la apropiación de su trabajo místico define una relación expresada en el idioma del intercambio, parece corresponder mucho más a nociones marxistas de las relaciones sociales, mediadas por la transacción de mercancías, que a una imagen maussiana de intercambio de dones" (Palmié 2002: 173).

El complejo fetichista kongo ("palo monte" en Cuba) resulta de gran inspiración para entender la constitución heterogénea y la eficacia de un poder sacerdotal que captura momias y otros restos humanos de "gentiles", "abuelos" o "antiguos", para hacerlos "trabajar" a su favor, más aún en un contexto como el atacameño donde los "gentiles" están significados como entes poderosos que se debe respetar $y$ temer. Sin embargo, y al igual que con los nfumbi (muertos) de los fetiches kongo, cualquier manipulación del objeto que singulariza la entidad implicará retribución o pago, so pena de ver su poder volcado en contra del incauto, que es lo que dicen le ocurrió a Le Paige, por no pagar por la manipulación indiscriminada que hacía de los "gentiles": "Tratadas impropiamente, las ngangas pueden volverse inefectivas. Pero también pueden volcarse en contra de sus dueños, consumir sus personas en una transformación fantasmagórica de la imagen hegeliana de la dialéctica de dependencia entre amo y esclavo" (Palmié 


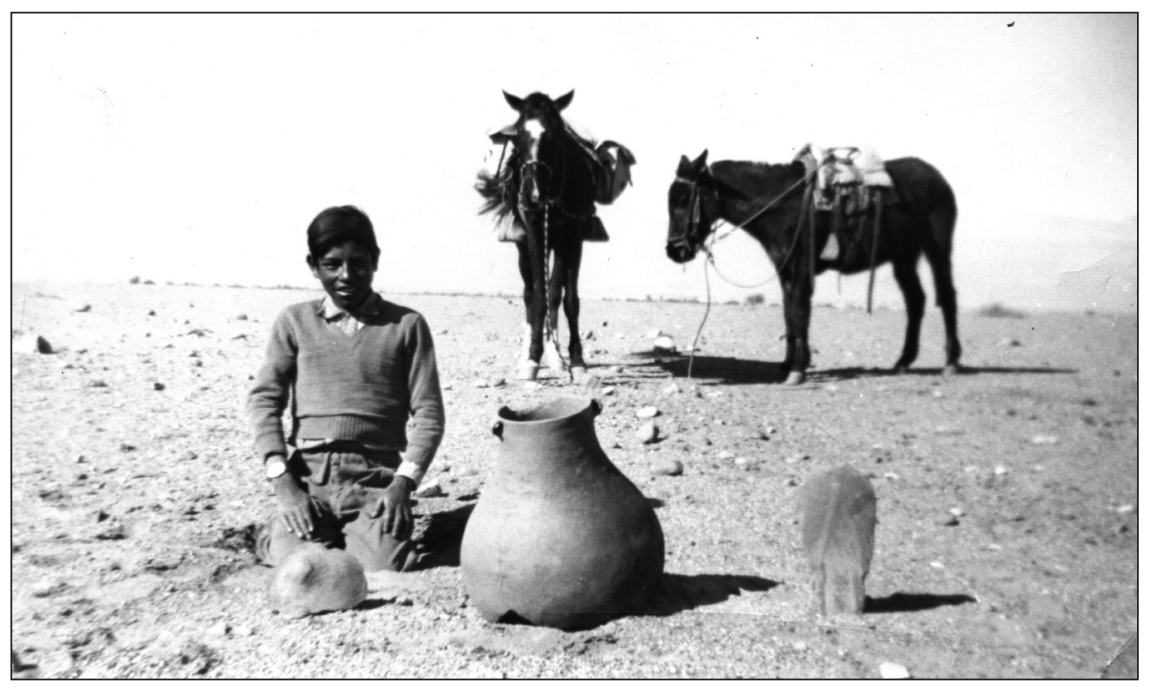

Figura 8. Luis Barboza, primer ayudante de Le Paige, 1957.

2002: 176). En Atacama como en el Kwango, el tipo de relaciones que se expresan en un sistema de fuerzas mágicas y fetiches, parecen aludir directamente a la desestructuración de los poderes políticos y las corporaciones constituidas en torno a entidades sacralizadas (como los malkus en los Andes), produciéndose un auge de la "brujería" como forma de personificar los objetos sagrados o sacralizar a las personas, un proceso de objetivación propio de las situaciones de crisis y desestructuración colonial, ruptura y transformación del contrato social.

Al transformar los espíritus de "antiguos" no bautizados (gentiles) en objetos arqueológicos o "cuerpos deshidratados", estos se vuelven "momias" con una identidad definida por los sistemas arqueológicos de clasificación y difusión, se vuelven las cosas sobre las cuales se inscribe el discurso autorizado y la "memoria de la disciplina" (Oliver, en Fabian 2010). En este sistema, cada momia se vuelve como un ídolo o "cosa-dios" singular, como fetiche de la disciplina con su historia, sus marcas, su biografía individualizada desde su exhumación. Se trata entonces de varios usos potenciales de este retrato indicial cosificado del atacameño, que la sociedad atacameña había querido vedar a la vista de los otros. Las momias se vuelven al mismo tiempo fetiches de culto patrimonial y mercancía de exhibición museográfica, en tanto objetos identificados y censados por el sacerdote arqueólogo y museógrafo, la disciplina científica, la doctrina cristia- na y el arte de la exhibición. La producción icónica de las momias se vuelve iconoclasta y a la vez idólatra, ya que se "descubre" una propiedad atacameña que estaba re-cubierta por la prohibición mágica del contacto y se ofrece para un nuevo culto de los orígenes nacionales chilenos.

\section{* Niños y fetiches: trabajo y disciplina, FILIACIÓN Y CONVERSIÓN}

Como señalaron varios de los atacameños citados más arriba, la infancia constituye el primer momento de formación de un imaginario sobre los "abuelos", "antiguos" o "gentiles", seguramente porque la infancia es también el estado "humano" más afín a la condición de "gentil", la que no responde aún a las normas domesticadoras y a un orden civilizatorio. Por la cercanía de los gentilares a los lugares habitados, abundan historias de niños que encuentran huesos humanos, de ahí la necesidad de historias edificantes que establezcan y trasmitan la prohibición de contacto y las consecuencias de su transgresión. El "padre" Le Paige decidió usar precisamente a los niños, su curiosidad lúdica y su conocimiento de los terrenos no cultivados, para el rastreo y excavación de cementerios en la cuenca del Salar de Atacama. Entre estos niños que buscaban tumbas y cargaban las bolsas de cráneos recogidas en las excavaciones, Le Paige menciona a varios: Luis Barboza, el primero con el cual recorrió el desierto (Le Paige 


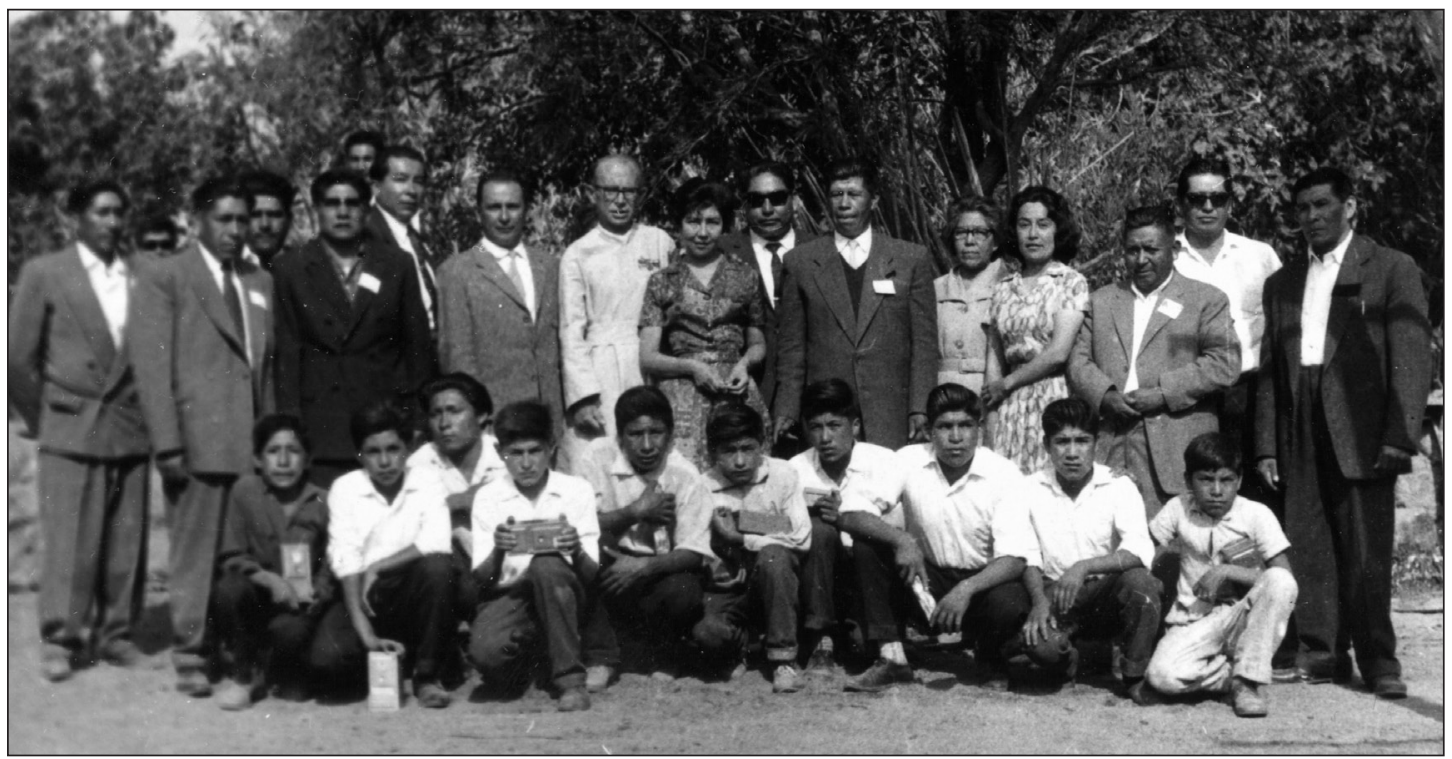

Figura 9. Línea de arriba: adultos miembros de la Asociación Hijos del Valle. Línea de abajo, jóvenes atacameños con alcancía en la mano, de izquierda a derecha: Santiago Acosta, Alejandro Cruz, Sebastián Ossandón, Alejandro Abán, Abelino Ossandón, Genaro Mamani, ¿? Cruz, Fiorentino Comperchoy.

1961: 19; Figura 8); Manuel Abán, uno de los que trabajó durante más tiempo con él junto a Eulogio Cervantes; Juan Salva, quien lo acompañó con la exposición de 1969 a Santiago; los varios muchachos que envió al seminario de La Serena a estudiar para sacerdote -Santiago Acosta, Alejandro Abán, Avelino y Rolando Ossándon, Jorge Cervantes, Fiorentino y Humberto Cumpencheir-; y otros como Hector Ramírez, Santiago Ramos, Tomás Cruz y Timoteo Cruz, que hasta hoy trabajan en el museo. ${ }^{31}$

El trabajo de colecta de objetos junto a los niños atacameños también responde a una pedagogía colonial, orientada tanto a la museificación cultural como a la conversión religiosa. El trabajo en excavaciones parece haber sido el primer paso positivista en una carrera de conversión que debía culminar en la generación de sacerdotes atacameños, tal como lo había hecho con sacerdotes congoleses. De hecho, este parece haber sido el sermón programático de su primera misa en San Pedro: el sacerdocio local como prioridad de la evangelización, "el quería que haya un curita netamente del pueblo, esa era la misión de él, que no venga un curita de afuera". $3^{2}$ Le Paige consiguió

\footnotetext{
${ }^{31}$ Com. pers. Santiago Ramos, 2011.

32 Entrevista a Manuel Corante, por H. Gundermann, 1998.
}

enviar siete jóvenes al seminario de La Serena, y uno de ellos llegó hasta Santiago, pero todos se retiraron, lo que parece haber sido una de sus grandes frustraciones. ${ }^{33}$

Así, como en muchas relaciones etnográficas fundacionales, lo que es presentado como el resultado de una relación de gratuidad dialógica constituye parte de un sistema de intercambios económicos y de favores clientelares. Varios testimonios apuntan a las ofertas materiales que Le Paige le hacía a niños, jóvenes y adultos. Un informante atacameño de Ayala (2008: 106) señala: "él les preguntaba por un sitio y la gente a veces por necesidad -muchas veces comprensible-- le decía del lugar, y él le daba, que sé yo, harina... Yo siempre he dicho que el padre Le Paige no descubrió nada, sino que él llegó a esos lugares porque la misma gente le entregaba los antecedentes". Para la inauguración del Museo en 1963, el sacerdote le entrega una alcancía a diez jóvenes cercanos a él, los llamados "hijos de Le Paige", y que posan para la ocasión junto a los socios adultos de la Asociación Hijos del Valle (Figura 9). Manuel Corante por su parte señala que Le Paige "descubrió mucho y pagaba. Aquellos que

33 Com. pers. Héctor Ramírez, 2010. 
traigan entierros, pasen datos donde hay momias para surtir el museo... a partir de un muchacho se encontró un vaso de oro, y el cura le regaló un terno, él al muchacho, ese muchacho era un... Genaro Mamani". ${ }^{4}$ El escritor Salvador Reyes, amigo y admirador del cura, escribe en su clásico Andanzas por el desierto de Atacama:

"San Pedro es un pueblo pobre y los niños carecen de diversiones. El padre tiene en su casa juguetes, libros, revistas, para ellos. Niños y muchachos de toda edad juegan, los unos al pinpón, los otros a las damas; los más pequeños hacen saltar un objeto que debe caer dentro de un vaso, componen rompecabezas... en el patio los muchachos juegan al fútbol, las chicas cantan para dormir a una pobre muñeca de trapo" (Reyes 1969: 162-163).

El arqueólogo Lautaro Núñez nos contó que el sacerdote le pagaba sueldos a los niños y jóvenes, sueldos que cobraban directamente sus padres. Pero no cobraban el sueldo completo, sino que, cuando tenían necesidades económicas iban a ver al padre, y éste les entregaba lo que necesitaban, sacando dinero de sobres que llevaban el nombre de cada ayudante. Como el "sueldo" del niño se acababa casi siempre antes de fin de mes, Le Paige introducía dinero adicional en los sobres, así siempre habría cuando el padre de un niño iba a solicitar algún efectivo..$^{35}$ De esta manera, en vez de "pagarle" a los "gentiles" por removerlos de la tierra y beneficiarse de su potencia, el sacerdote le pagaba a los niños, como trabajadores a su servicio, para realizar justamente la operación de traslado de los muertos desde el espacio tabuizado del cementerio -el gentilar- al espacio de exhibición y fetichización -el museo como moderno gentilar-. Esta operación habría sido implícitamente aceptada por los padres de los niños, no solo por el temor que infundía una autoridad eclesiástica, análogo al miedo que infundía el contacto con los muertos, sino también por causa de la protección que ofrecía el sacerdote ante otra amenaza quizás mayor, la de la clase comerciante afuerina (de origen yugoslavo) cuyo éxito económico y política de alianzas le había permitido comprar tierras y volverse un poder terrateniente que ejercía su dominio sobre el pueblo. Así, acorralados ante estos tres poderes ("gentiles", sacerdote y comerciantesterratenientes), los atacameños más pobres habrían optado por entregar los niños y los "gentiles" al sacerdote

\footnotetext{
34 Entrevista a Manuel Corante, por H. Gundermann, 1998.

35 Com. pers. Lautaro Núñez, 2011.
}

arqueólogo a cambio de su protección frente a los abusos y acciones expropiatorias de los terratenientes. ${ }^{36}$

Santiago Ramos, quien fuera uno de los que fue niño ayudante de Le Paige, subraya la ruptura del padre con la prohibición de contacto con los "abuelos", y el cambio que esto implicó en las concepciones de los niños y jóvenes:

"no escalar los cerros porque es parte de ellos [el Inka, los "antiguos"] respetaban los cementerios de acá de San Pedro... que eso no se podía tomar, incluso si había una cerámica superficial ahí, no se podía tomar, porque no deberia tomarse no má, eso era de los abuelos, y ellos se enojaban cuando se tomaba eso... entonces nosotros nos criaron con eso... por eso que nunca tomamos nada... y el Padre Le Paige nos cambió un poco, porque dijo que no le hacía nada... y era verdad poh!... el padre Le Paige, él tomaba cualquier cosa, los cuerposy nunca le paso na y bueno igual a nosotros... pero si con el mayor respeto debido a los cuerpos".37

La hipótesis fetichista expresada más arriba permite entender la soberanía indiscutida del sacerdote sobre la comunidad, como producto de la captura y concentración de los "gentiles" y de su poder en un museo que opera como un fetiche nganga, "singular por su composición íntima... multiplicidad hecha uno, diversidad condensada", ofreciendo la "impresión visual de la contención" como "suma de todo lo que le acontece", perpetuando así la fuerza y dominación de su dueño (Bazin 2008: 504, 537 y 542). Sin embargo, el sistema de intercambios auráticos entre el sacerdote y el fetiche requiere la inclusión de un tercero, los niños, indispensables como mediadores entre el sacerdote y la comunidad, y como fuerza de trabajo secular dedicada a la "alimentación" del fetiche, es decir, al ejercicio desacralizado de la "profanación" de tumbas, concebido como juego, intercambio de bienes o ejercicio disciplinario de obediencia al "padre".

Los niños son convertidos así en operadores de la transformación religiosa, alimentando la producción del museo-nganga, donde los muertos al igual que los niños trabajan para Le Paige, produciendo una carga de maná (fuerza mágica, potencia de individuación del fetiche) que se expresa como soberanía hobbesiana, como un Estado

\footnotetext{
${ }^{36}$ Com. pers. Cristina Garrido, 2012.

37 Entrevista a Santiago Ramos, por H. Gundermann, 1998.
} 
que se origina y reproduce por el miedo de la comunidad (Esposito 2007). Las momias pierden su soberanía como gentiles y son puestas a trabajar como esclavas del museo en la producción del maná de su dueño. Esta lectura es coherente con el sistema de transformaciones semióticas en torno a los "dioses de los cerros" tal como lo presentó Gabriel Martínez (1983) para los cultos andinos. Cada cero (malku) o "gentil" va a ocupar un lugar en el intervalo entre las potencias de creación-destrucción (significadas como waka) y las potencias de conservación-no-creación (significadas como no-waka), siendo toda divinidad o chullpa (malku o "gentil") una combinación de waka y no-waka. La captura de los gentiles y su instalación en el espacio del museo (o nganga) va a posibilitar la inversión interna de la dimensión waka del "gentil" en no-waka, y de esta manera, el control de la temporalidad asociada a los gentiles, de manera que la dimensión conservadora/ no-creadora del tiempo (que Martínez describe como "lineal", o cronológica) se imponga sobre la dimensión creadora/destructora (descrita como "cíclica"; para nosotros "comprimida" o heterocrónica). Así se impone la concepción arqueológica evolucionista y linear del tiempo y la vida, y la disciplina arqueológica como administradora cultural de la muerte y la historia. Para el éxito de esta operación, resultó importante convocar a los niños, llamados a enfrentar directamente las concepciones y los objetos de la muerte.

En su interpretación del churinga, Giorgio Agamben identifica este objeto mágico melanesio junto a los juguetes, como significantes inestables del tiempo. El rito y el juego constituyen mecanismos de transformación de la diacronía en sincronía (en el caso del rito, donde opera el churinga) y de la sincronía en diacronía (en el caso del juego, donde opera el juguete), formando en conjunto una máquina binaria de doble tendencia, orientada a producir diferenciación del tiempo o "distancia diferencial", es decir, historia o tiempo humano (Agamben 1978: 142). Los mecanismos transformatorios pueden volver los significantes inestables en significantes estables: la "larva" por ejemplo, "significante inestable oscilante entre sincronía y diacronía, se transforma en lare, máscara e imagen esculpida del ancestro: significante estable que garantiza la continuidad del sistema". La larva vuelta máscara deviene así en "imagen del muerto... apariencia, sombra o reflejo especular", significante de la sincronía que deviene en diacronía de la "errancia perpetua", un "espectro del muerto sin sepultura" (Agamben 1978: 149-151). Los ritos funerarios permiten la estabilización de los significantes: la larva, inestable, debe volverse un muerto, significante estabilizado. El juego, al revés, desestabiliza los significantes. Por eso, niños y larvas comparten un carácter inestable, representando la continuidad y la diferencia entre dos mundos, frente a los adultos y los muertos, quienes significan la estabilidad. El niño muestra que el ancestro no está vivo, y la larva muestra la "vida" del ancestro muerto; de ahí el sentido de un tabú de los muertos o "gentiles", que permite mantener la equivalencia entre objetos animados (cadáveres, restos materiales) y sujetos muertos (los "abuelos", los "antiguos"). Ambos, niños y larvas, se vuelven garantías de la oposición misma, de un "salto cuántico" en el "intervalo diferencial" que hace posible la sociedad y el tiempo humano, la diferencia significante entre diacronía y sincronía, entre el tiempo cronológico y el tiempo ayónico, entre vivos y muertos, cultura y naturaleza. Por eso, la importancia de usar los niños para invertir el rito fúnebre, inversión que se vuelve un juego y que permite operar la transformación del gentil (muerto/adulto) en imagen (momia/máscara) espectral de los muertos. La forma fósil de los muertos, forma de identidad que deja subsistir en el tiempo las semejanzas, contribuye a la concepción de la cultura atacameña como un conjunto significante estabilizado, generando un doble efecto: en tanto ícono o momia fetiche, refuerza la potencia del sacerdote como científico (por el valor del fetiche en el sistema disciplinario de la etnología); y en tanto índice de la cultura, captura y estabiliza el lugar de los atacameños en la diacronía evolutiva del tiempo unilinear, evacuándolos de la sincronía del presente, por medio del efecto de con-vivencia en una misma temporalidad de juguete, de los niños con momias prehistóricas (Fabian 1983) (Figuras 10 y 11). En los años cincuenta, la arqueóloga Grete Mostny (1968: 132-133) encuentra un tipo de objeto atacameño que recuerda el churinga melanesio, los llamados "santos de los antiguos", un tipo de piedra alargada que se ubica al borde de los campos o enterrada, para la protección de los espacios. Estos "santos" de piedra (como la "piedra del rayo", es decir, el "santo" del rayo) permitían precisamente la materialización del diferencial de tiempo evidenciando la inmanencia de los "antiguos" en el tiempo y espacio de lo contemporáneo. Le Paige, al incorporar a los niños mediante el juego, en la reinscripción del tiempo pasado, y exponer museográficamente los muertos deshidratados (es decir, en su 


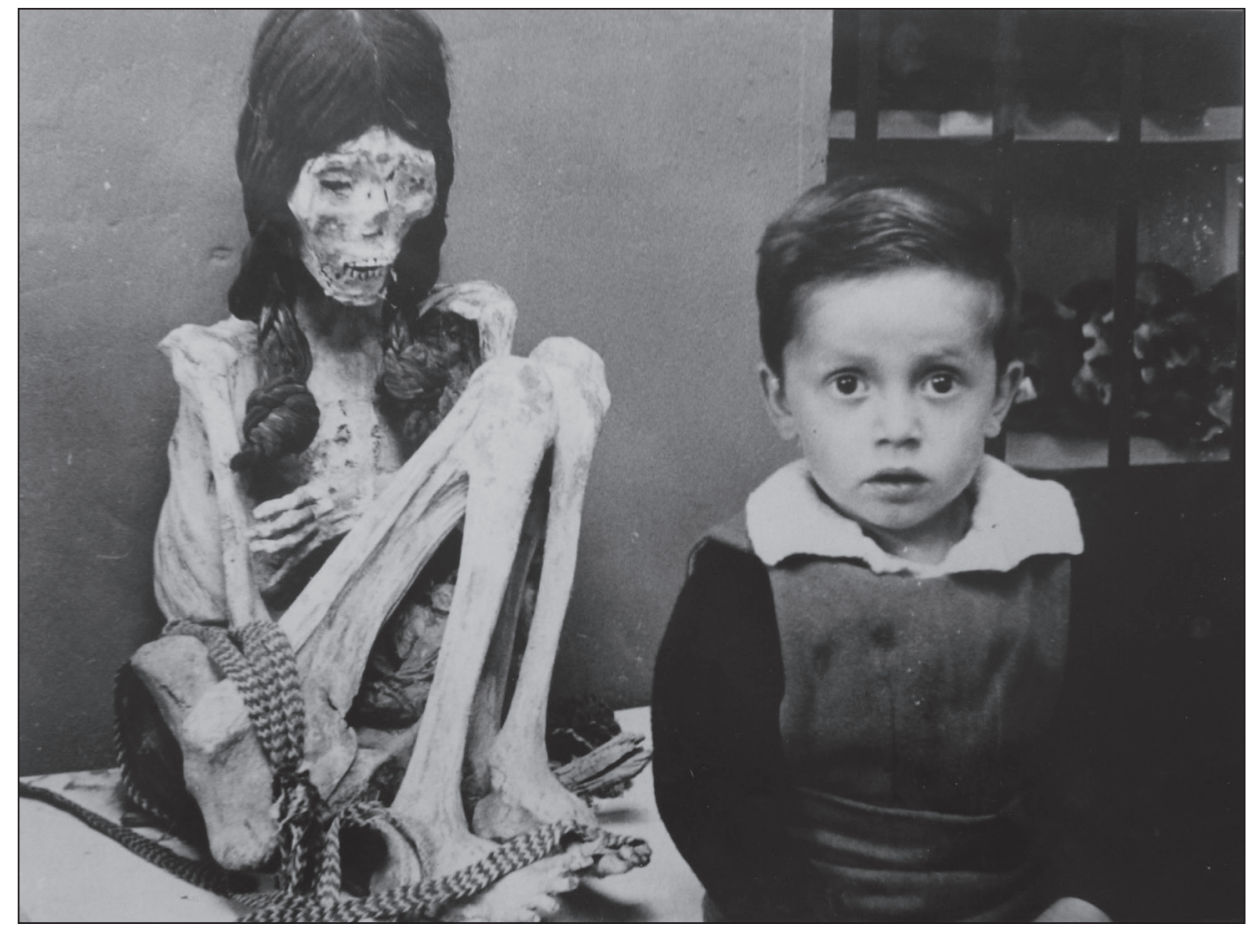

Figura 10. Niño con momia.

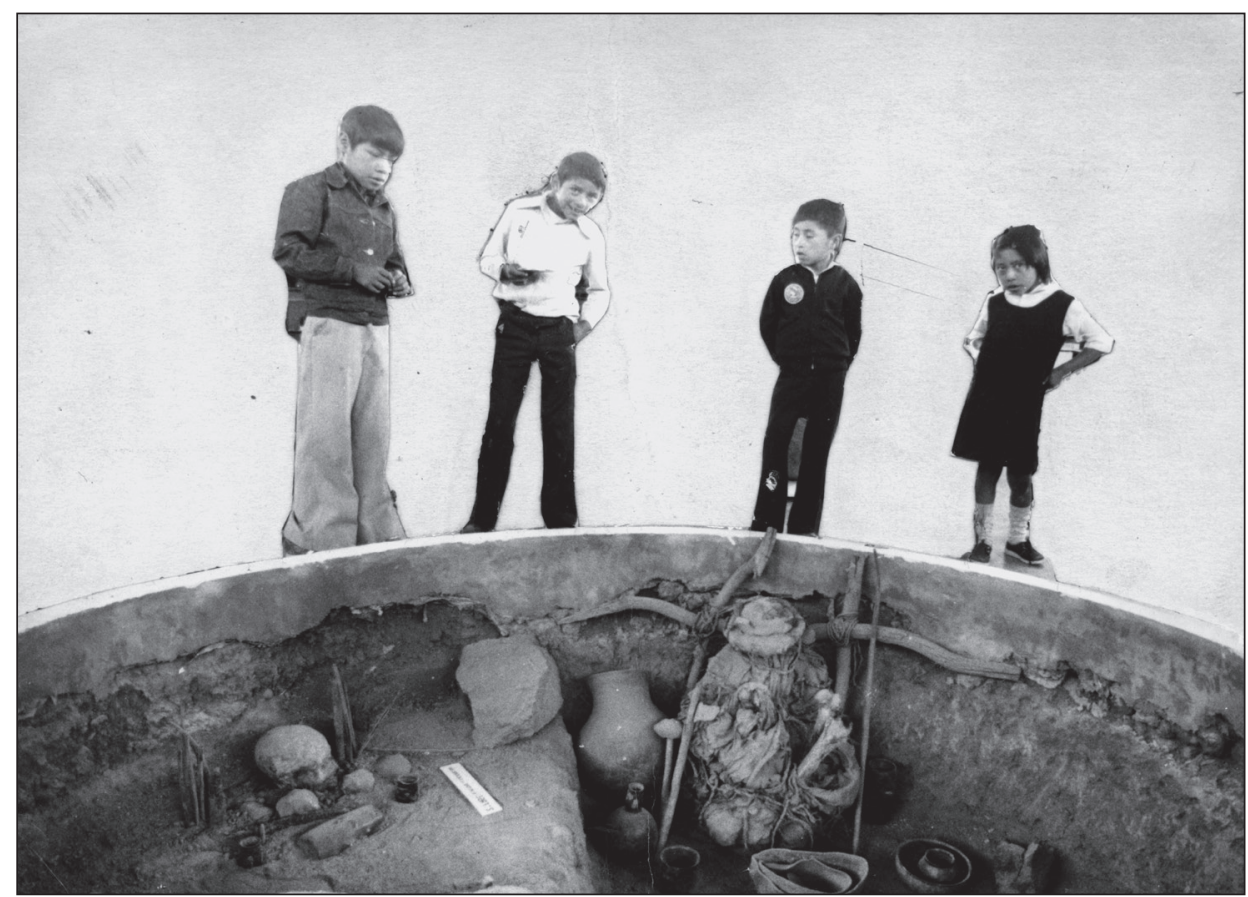

Figura 11. Collage de niños y exhibición de excavación con momia. 
dimensión menos larval), rompe con una estructura de transformaciones y equivalencias, proyectando las momias como evidencias de una continuidad temporal. Con una maquinaria museal de definición de límites cronológicos y evolutivos, rescata el potencial fosil de la momia como juguete, controlando la afinidad entre el niño y la larva, para dominar como fuerza conservadora a los adultos y los muertos.

\section{* Economías de la exhibición, el tributo y LA DISCIPLINA}

El clientelismo, la compra y venta de bienes y servicios, la asalarización de los trabajadores y las diferentes prácticas intercambiarias que fomentaba, harán de Gustavo Le Paige un agente importante en la transición económica y demográfica que se observa en el salar de Atacama a mediados de la década del cincuenta (Rivera 1994: 189). Como han señalado varios estudios, a principio de los años treinta se había consolidado el peso de la minería en la economía atacameña, especialmente por el crecimiento de la mina de Chuquicamata. Si bien la explotación de llareta y el comercio arriero de ganado irán declinando a mediados de siglo (por la construcción de ferrocarriles en los años cuarenta), estas fuentes de ingresos e intercambio serán sustituidas por la creciente contratación de obreros atacameños en las faenas de Chuquicamata y también por la venta de la producción agrícola local (frutas y verduras) consumidas por el campamento de la mina. Así también, a partir de los años cuarenta se observa una mayor presencia del Estado en la región del salar de Atacama, construyendo rutas, pozos y plantas eléctricas, respondiendo también a las demandas de las organizaciones locales, que solicitan escuelas, retenes y hoteles. A la creciente presencia del Estado se sumarán el episcopado y la Universidad del Norte con el Plan Cordillera (1955) destinado a la reactivación agrícola, y los primeros "turistas", principalmente residentes de Chuquicamata. En este sentido, durante el siglo XX el desarrollo de la región fue siempre pensado en estrecha dependencia de la minería regional, primero de las salitreras hasta los años veinte, y luego de la mina de Chuquicamata (Rudolf 1951; Mostny 1954; Núñez 1991; Mondaca et al. 2011; Bengoa 2004: 185-192).

En sus primeros años en San Pedro, Gustavo Le Paige, como párroco del pueblo, habló de la creación de una in- dustria de conservas que sin embargo nunca se concretó. ${ }^{38}$ Luego consigue un generador eléctrico que manejará personalmente (Toconao ya disponía de una planta eléctrica); renueva la cancha de fútbol inaugurándola con la visita del club Colo-Colo (1966); crea la primera hostería de San Pedro, respondiendo a una creciente demanda del turismo ya en ciernes en esa época; logra atraer una estación meteorológica de la Fuerza Aérea de Chile, estación que él mismo dirigirá; apoya las gestiones para la canalización del riego, iniciadas con el presidente González Videla (1958) y terminadas con Eduardo Frei (1964); apoya un proyecto de reforestación de 5.000 hectáreas con tamarugos que permitirían según él "transformar la zona en un vergel" y "erradicar la cesantía en San Pedro". 39 Junto a la Asociación de los Hijos del Valle, inicia las gestiones para la construcción de un hospital (1970) que finalmente será una Posta, todo esto enmarcado en su presidencia del Centro para el Progreso, organización demócrata-cristiana fomentada por el gobierno de los Estados Unidos como alternativa a las vías socialistas al desarrollo (Alianza para el Progreso) (Madrid de Colin 1965: 20). Además, dirigirá el Club Juvenil, los padres y apoderados de la escuela pública, la Cruz Roja y la asociación de fútbol. Todas estas gestiones, sumadas a sus problemas con varios funcionarios públicos que amenazaban su dominio, y la permanente oferta de bienes materiales a los habitantes pobres, explican el título de "gerente general" en El último rey (Du Brulle 2010).

Aunque el mismo Le Paige señalara que su prioridad vocacional eran los feligreses y no el Museo (Madrid de Colin 1965), es sin embargo su operación museográfica la que permite entender mejor una lógica más general de intercambio y auratización de los objetos donde, en conjunto con el desarrollo de los aparatos y archivos disciplinarios de captura y procesamiento de información, Le Paige inserta la materialidad cultural atacameña. En esta lógica se mezclan y combinan las prácticas del don estatutario a los poderes monárquicos y coloniales, la mercantilización de los objetos-cosas en un mercado científico donde los vestigios otorgan prestigio y poder, y la re-calificación cultural de los objetos auratizados por el valor cultural del tabú, en objetos auratizados por su valor de exhibición

\footnotetext{
${ }^{38}$ Entrevista a Manuel Corante por H. Gundermann, 1998.

39 ElMercurio, "Experimentan reforestación en San Pedro de Atacama”, 1/o6/1968.
} 
como "herencia" patrimonial, herencia que es "descubrimiento" de un "origen", de las raíces materiales de algo tan metafísico como la "patria", la "raza" o la "cultura".

La colección de objetos de arte y etnografía entregada por Le Paige al Musée Royal d'Afrique Centrale de Tervuren, constituye su principal legado a la museología colonial belga, y este gesto de donación marcará duraderamente la política antropológica del misionero investigador. Más aún, el gesto lo inscribe como agente de una red institucional mundial de intercambio y acumulación de objetos artístico-religiosos "primitivos" o "tribales"; red que tenía y tiene hasta hoy a Bélgica como el mayor acumulador de arte africano en el mundo (Corbey 2000). El Musée ethnographique de la Mission du Kwango, por ejemplo, reunía en 1938 una colección de 2.400 piezas acumuladas desde 1895 gracias a los envíos de los misioneros. De estas piezas, se hará una exposición en la Maison de l'Aucam, y un número especial de la revista donde el conservador del Museo, el jesuita M. Colas, señala que las piezas etnográficas son expuestas "cargadas de sus insignias y amuletos, cubiertas de la sangre de las víctimas o de la tierra roja de las incantaciones", y como no hay "arte por el arte" en África, tienen "valor de documento" (Colas 1938: 77). Aquí nuevamente y en el seno de la Compañía de Jesús, aparece la recolección de objetos en el marco de la constitución de un archivo de los poderes religiosos, un archivo que se propone la captura de estos poderes, sin intentar su transformación como lo proponía Le Paige.

Como señalamos más arriba, en 1957 Le Paige abre la casa parroquial para exhibir los centenares de piezas que había colectado en dos años de excavaciones, inauguración que hará coincidir con la fiesta de San Pedro de ese año. En el primer número de la revista atacameña El Cholulo, publicado el mes de la inauguración, el cura museógrafo explica su concepción de un museo atacameño o lican antai (sic):

"Un museo no debe ser una colección muerta de objetos antiguos; debe ser vivo, el complemento del pueblo que nos dejó sus vestigios, no solo en objetos transportables, sino en sus ruinas y diferentes maneras de vivir... Un museo debe ser capaz de facilitar a todos los que lo visiten la oportunidad de llegar a todos los lugares de los cuales vienen los vestigios ofotografías, dibujos y documentación".40

\footnotetext{
40 "Museo de San Pedro de Atacama", por G. Le Paige, El Chululo, 29/06/1957, núm. 1. Ese preciso día se celebra el aniversario de
}

Esta concepción abierta del Museo que funcionará hasta finales del año 1962, se transformará más adelante en una política de protección y control, ante el aumento de afluencia a los sitios "saqueados por turistas", como acostumbrará a decir 15 años después (Le Paige 1977), al punto de llegar a no querer revelar a nadie los sitios de sus hallazgos por temor a estos "saqueos". De alguna manera, la ambición panóptica que rige la distribución y exhibición de la materialidad cultural en el espacio del museo (Bennet 1995), orientada al control de "robos", es decir, al control del afecto aurático o culto fetichista de los objetos que produce la compulsión por su apropiación, se va a extender a todo el territorio atacameño, al punto que cualquier apropiación de objetos por algún otro agente ("turista", arqueólogo, u otro) va a ser considerado como "robo" o "saqueo", y ser anotado sistemáticamente en el registro científico de sitios y tumbas "saqueada por turistas" (Le Paige 1977: 114-124). La disciplina del control arqueológico concurre así a la potenciación del sujeto europeo soberano en el colonialismo republicano chileno, al punto de hacer valer un derecho de soberanía en torno a las fronteras geo-disciplinarias, como las que van a separar oficialmente los territorios de Le Paige de los de su competencia Georges Sarracino. ${ }^{41}$ Vemos entonces las etapas de transformación del afán del misionero. Mientras que en África propone la transformación del arte nativo, en una suerte de poiesis de aculturación cristiana, en Atacama, se dedicará a la captura y monumentalización (fetichización) de la materialidad existente; pero dentro de este marco atacameño, pasará de una idea de museo abierto, como imagen indicial de un territorio soberano, a la idea del cierre, registro y control disciplinario de todos los "bienes" arqueológicos, tanto del museo como del conjunto del territorio. De esta manera se pueden leer los numerosos artículos científicos publicados por Le Paige entre los años 55 y 80 , como un gran inventario cartográfico y estratigráfico de registro e identificación de las miles de "piezas"

San Pedro, con la inauguración del nuevo Museo Arqueológico. Entre los visitantes ilustres que contará este museo en la casa parroquial se cuentan al arqueólogo austriaco Osvaldo Menghin (radicado en Argentina entre 1948 y 1973) y la BBC de Londres, en 1959.

${ }^{41} \mathrm{G}$. Sarracino fue un sacerdote que se asoció al proyecto arqueológico de Le Paige en los años setenta, hasta que las desavenencias entre ellos llevaron a Le Paige a solicitar su expulsión del territorio del salar. 


\begin{tabular}{|l|l|}
\hline Grupo de Tocopilla (Liceo) (1961) & Una aguja de hueso con personaje sentado (tenemos foto en color) \\
\hline Niño de R.S. (Chuqui) & Una Tableta para rapé de la momia no. 2532 \\
\hline Grupo obreros C.D.O. (de Calama) 18-IX-62 & Una Tableta para rapé Quitor 5 Tumba no. 1945 (tenemos foto) \\
\hline $\begin{array}{l}\text { Grupo Profesores de Chuqui } \\
\text { Todo fue recuperado a tiempo antes que se escape la... 20-X-62 }\end{array}$ & $\begin{array}{l}\text { Una espatula de hueso con representación del sacrificio de la cabeza (tenemos } \\
\text { varias fotos) } \\
\text { Otra espátula de hueso } \\
\text { Un Tapón de madera con escultura de una llamita }\end{array}$ \\
\hline Capitán de Reg. con familia & 2 Tabletas para rapé \\
\hline Escuela Off. Pedro Valdivia. Dic. 66 & 120 objetos (recuperados) \\
\hline
\end{tabular}

Tabla 1. "Robos".

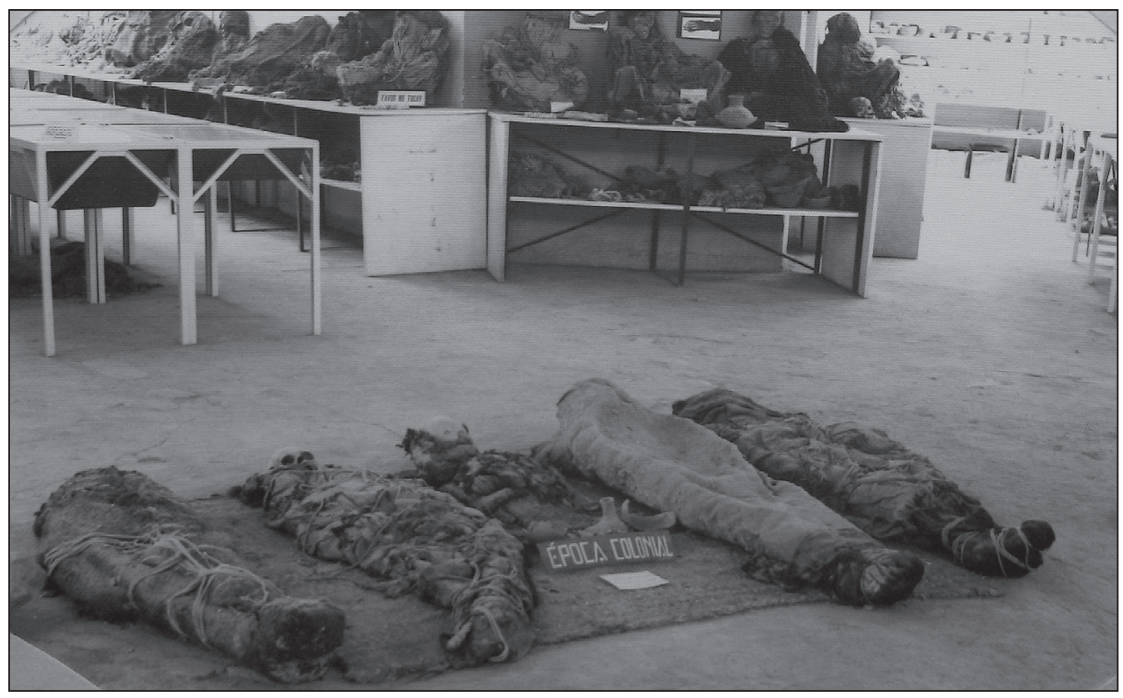

Figura 12. Exhibición de momias prehispánicas y coloniales, inaugurada en 1963 con ocasión del Simposio Internacional de Arqueología. Archivo IIAM.

encontradas en el desierto, un inventario contable y auditable de la riqueza arqueológica del subsuelo del salar de Atacama, orientado a la producción e inscripción del territorio como fuente de bienes patrimoniales de propiedad chilena (y de la cual el sacerdote se autoproclama como principal garante).

Asi como la soberanía requiere patrimonio, el desarrollo disciplinario requiere control. En términos de propiedad, esto implica la búsqueda e identificación de ladrones y robos. En esos años, Le Paige empieza a preocuparse por la desaparición de objetos de la exhibi- ción. Él mismo le pasaba las llaves del museo a los visitantes y algunos se robaban objetos. Entonces escribía un cartelito que señalaba: "robado por tal delegación". Hacia 1961, ya hacía listas de dos columnas, donde registraba los robos (ver Tabla 1). En muchos caso, anotaba "tenemos foto" del objeto robado, haciendo de la fotografía otro instrumento clave de su saber-poder en el marco de enormes cantidades de objetos pequeños y grandes expuestos sobre grandes y alargados tablones en las salas del museo (Figura 12 y 13). El conocimiento visual del panóptico museal era clave para el control de los objetos. 


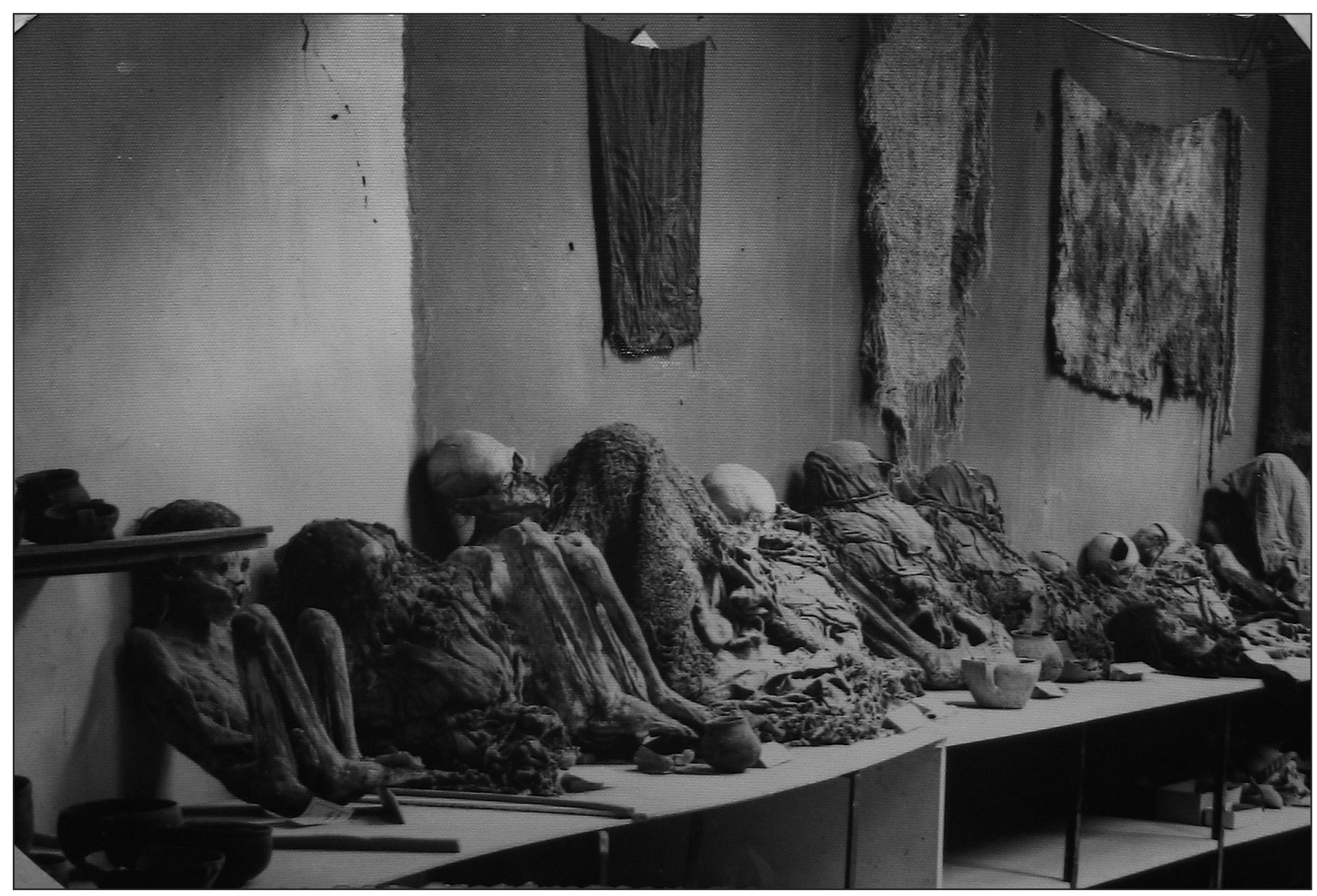

Figura 13. Exhibición de momias y ajuares funerarios, con ocasión del Simposio Internacional de Arqueología. Archivo IIAM.

En 1964 se firma el acuerdo con la Universidad del Norte para incorporar el Museo a la institución universitaria, lo que le permite en 1965 obtener 105 vitrinas para proteger las colecciones. La incorporación a la academia se relaciona directamente con la constitución de la colección como una "propiedad" con valor de cambio, es decir un capital ya no solo manático, de potencia fetichista, sino también de valor disciplinario y económico. La potencia soberana pasa a conjugarse con el poder disciplinario para fortalecer definitivamente la posición y el trabajo político de Le Paige. Dos años después, recibe la visita del presidente Frei, de quien obtiene apoyo para la construcción de la segunda sección del museo, que se inaugura al año siguiente junto al Congreso Panamericano de Arqueología, y que dedica exclusivamente al material "paleolítico".

Para esos años, Le Paige ya está en campaña contra los saqueadores y destructores de vestigios. En una nota de El Mercurio, Salvador Reyes apoya a Le Paige en sus denuncias de saqueos ("huaqueos"), destrucción de petro- glifos para extracción de piedras cerca de Calama, robo de joyas en tumbas de Pica 7 con tractores que de paso destruyen cerámicas, y en petroglifos de la quebrada de Tarapacá por dinamitamiento. También menciona un "arqueólogo extranjero" que se llevó objetos de la desembocadura del río Loa, y las fotografías del pukara de Lasana destruido por entretención de los visitantes, y concluye con una frase que podría ser del mismo Le Paige: "los más 'educados' son los más bárbaros". ${ }^{42}$ Esta "cruzada" por la patrimonialización de los vestigios, es en el fondo la transformación del territorio atacameño en un espacio "protegido" como propiedad individualizable y contable en todos sus elementos arqueológicos, suceptibles de algún valor científico. Sin embargo, en la medida que la forma de control y poder del sacerdote en Atacama se volvía cada vez más institucional, disciplinaria y "moderna", el museo y sus colecciones irradiaba

\footnotetext{
${ }^{42}$ El Mercurio (Santiago), "Gloria y desastre de la arqueología", por Salvador Reyes, 5/06/1968.
} 
e hipnotizaba en forma casi mágica hacia el país entero, imaginaria y materialmente, logrando la inscripción de San Pedro de Atacama y la "cultura atacameña" en el mapa geográfico y temporal del país. Para entonces, el soberano se ha apropiado completamente de los bienes culturales y de su posible negociación en un mercado (científico, político, artístico). Para la arqueología, alimenta sus clasificaciones, sus relaciones intra y extradisciplinarias, abasteciéndola de una colección de cráneos, cerámica, fósiles, cuerpos, y parafernalias. Esta colección patrimonializada por un aparato científico universitario va a alimentar tanto los circuitos de turismo transnacional como el desarrollo disciplinario de ciencias naturales y sociales. En enero del 63, se inaugura la primera rotonda del actual museo, con un recordado evento científico: un Simposio de arqueología con numerosos investigadores internacionales, financiado por la Dirección General de Turismo (Le Paige 1963). En este simposio, el clásico debate de los arqueólogos andinistas entre continuidad y discontinuidad cultural se expresó en la polémica entre el anfitrión Gustavo Le Paige, autodidacta y defensor de la "continuidad de la cultura atacameña", y el profesional Mario Orellana, defensor de las recientes tendencias neopositivistas de nominación "tipo-sitio", para aplicarlas a la que quiere llamar "cultura San Pedro". ${ }^{3}$

Algunos detalles del debate son importantes para entender lo que está en juego en esta polémica. En primer lugar, los conceptos de "extranjero", "imperio" y "desarrollo" que aparecen en los argumentos. Para Le Paige, existe un peligro que combatir: el "minimizar la cultura atacameña, es decir, reducirla a una superposición de varias culturas que se habrían reunido solo por azar en San Pedro de Atacama, o presentarla como una extensión epigonal de aquellas culturas" (Le Paige, 1963: 8). Para enfrentar este doble "peligro", estudia series de proyectiles, cerámicas, tabletas de rapé, y cráneos, los que le van a servir para afirmar que:

"una vez finalizado el proceso de adaptación el atacameño de esta época tuvo la posibilidad y ocio para andar, conocer a los demás seres establecidos en esos lugares, iniciándose el intercambio, lo que representa una nueva dificultad para alounos que piensan

43 Las presentaciones de este debate fueron publicados en los Anales de la Universidad del Norte 2, 1963, "Congreso internacional de arqueología en San Pedro de Atacama”. que la cultura en el caso de la Atacameña, estaría formada únicamente de capas horizontales sobrepuestas, como si la llegada del español se hubiera sobrepuesto al atacameño haciéndole desaparecer, de la misma manera que el Inca, anteriormente, o el yankee actualmente. Cada uno de ellos contribuyen al desarrollo del grupo que quizás domina, pero no lo suprime" (Le Paige 1963: 14-15).

¿De qué está hecha entonces la cultura atacameña para Le Paige? ¿Qué es lo que se mantiene en el tiempo, sometido a los grupos que vienen a dominar al "atacameño"? Sin nunca explicitar su teoría racial, la idea de una esencia racial atacameña está en el eje del argumento continuista de Le Paige, por lo que aparece casi contra su intención:

"Podemos asegurar que no hay ruptura en la secuencia que hemos dibujado en el esquema de los cementerios de San Pedro, y que no es la desaparición de la alfarería negra pulida, a partir de Tchecar Sur, primer piso, lo que permitiría admitir un cambio del grupo racial autóctono; hay muchos otros elementos que demuestran lo contrario... Si consideramos a San Pedro como un lugar ideal de intercambio, un cruce necesario de relaciones entre varios grupos, eso postula un grupo autóctono que ha permitido tener ese papel" (Le Paige 1963: 14).

Aunque ofrece una sugerencia interesante sobre la mayor colección mundial de tabletas de rapé, como indicador de autonomía cultural, Le Paige pasa rápidamente a expresar sus espectativas raciológicas en torno a la antropometría: "desde el punto de vista de la craneología, iencontraremos en los índices cefálicos pruebas de cambios notables que revelen en el curso de la prehistoria atacameña la llegada de un nuevo y distinto grupo racial?". Sus datos lo llevan a percibir:

"hay continuación evolutiva perfectamente perceptible desde el Tulanense y el Altiplano S.O. de Bolivia hasta el Inca, pasando por el Mesolítico, el Neolítico primitivo, la invención de la cerámica, de la agricultura y domesticación de la llama (pinturas rupestres del Río Salado) y de los pueblos estables con toda su evolución de la vida clánica a la más individual que se puede imaginar" (Le Paige 1963: 23).

A modo de conclusión, aborda el problema de los "aportes extranjeros" a la cultura, proponiendo una comparación con el África central que percibe en su discontinuidad, a diferencia de lo que ve en Atacama, donde: 
"esos aportes no llenan nunca un vacío, como lo hemos probado en el Centro Africano donde las civilizaciones se sobrepusieron sin conocerse entre sí, llegando cada una donde ya había desaparecido la precedente. Si a veces un elemento desaparece como la alfarería negra pulida, otros elementos quedan probando la perfecta continuación. El más importante cambio se nota en la invasión pacífica de las Culturas del Altiplano de los siglos XIII$X V I$ sin poder, sin embargo, dominar al atacameño" (Le Paige 1963: 23).

La "existencia de un pueblo receptor que evolucionará gracias a esos aportes" extranjeros lo lleva a defender el nombre "atacameño" para la cultura que estudia y que tiene la forma de una raza. Ante este paradigma un tanto envejecido para entonces, Mario Orellana defenderá, sin éxito, dos principios básicos: 1) oponerse a la nominación étnica e implicaciones etnohistóricas de un nombre (Orellana 1963:31), lo que supone una defensa del ámbito disciplinario exclusivo de la arqueología para la definición de sus categorías, y 2) abordar las complejidades de la identificación de los habitantes, que son más localistas que lo que quisiera Le Paige u otros raciólogos (se identifican con ayllus y no con el conjunto). Así, ofrece tres razones para cambiar el nombre de "Cultura Atacameña" a "Cultura San Pedro": 1) "el nombre 'Cultura San Pedro' no implica nominar étnicamente a los integrantes de esa cultura, como ocurre con el de 'Cultura atacameña'" 2); "hace justicia" al lugar; 3 ) "es un nombre que se apoya en una denominación geográfica relativamente moderna y que, por lo tanto, no tiene implicaciones etno-históricas" (Orellana 1963: 31). Vemos así que Orellana quiere extremar las precauciones para fortalecer la autonomía de la designación arqueológica "tipo-sitio" frente a las tendencias etnicistas (etnológicas y etnohistóricas), las que tanto para Le Paige como para Orellana, constituyen argumentos raciológicos, donde la noción de etnia/cultura equivale a la de raza.

La diferencia entre Le Paige y Orellana se corresponde con lo que Diego Escolar observa en el Instituto de Investigaciones Arqueológicas y Museo (IIAM) de San Juan (Argentina), en torno al debate sobre el origen y presente de los huarpes, cuando señala que "con frecuencia, estos monumentos de continuidad aborigen [los Museos] son constituidos sobre los mismos sitios y objetos que los arqueólogos han instituido como referencias de culturas y sociedades prehistóricas desaparecidas, discontinuas o sin vínculo aparente con las poblaciones actuales" (Escolar 2007: 44). En este caso, Le Paige constituye una rareza, ya que se enfrenta al discurso arqueológico neopositivista de la discontinuidad para erigir él mismo las referencias monumentales de una "continuidad aborigen" entre la sociedad prehistórica y la población actual. Una teoría arqueológica de la continuidad étnica (racial) en dos a cincuenta mil años de prehistoria solo es posible en el marco de un paradigma soberano del poder y la herencia racial; mientras que una teoría de la discontinuidad, más común entre los arqueólogos de los cincuenta y sesenta como los que asistieron al Simposio de 1963 o los fundadores del IIAM de San Juan, es más afin al desarrollo disciplinario, mas dado a la producción de múltiples formas de individuación y diferenciación temporal y espacial. Esta producción de unidades discretas de tiempo y espacio (individuos, "culturas", o localidades, o la combinación de estas, como el tipo-sitio del "complejo San Pedro") se enfrentaba a las tendencias de explicación y comprensión tanto etnológicas como históricas, cuyas teorías se consideraron demasiado generales y especulativas, y una amenaza para la especificidad de la disciplina arqueológica. Asimismo, el paradigma "tipo-sitio" lleva la concepción del "área cultural" a su expresión más mínima, un tiempo y un espacio de incidencia delimitado al extremo.

Al igual que los huarpes de San Juan, los habitantes de San Pedro parecen no haber querido o podido reconocerse más como herederos de los "indios" ancestrales, los "atacameños" identificados por los arqueólogos durante el siglo XX (Uhle 1913; Latcham 1938; Gänger 2010), y optaron por una nacionalización campesinizada que les permitiera evitar el estigma estatal asociado a su clasificación como "indios" (Morales 2009; com. pers. Santiago Ramos 2010). El problema que enfrentó Le Paige no fue entonces producir los contenidos culturales de un etnónimo ya establecido, sino lograr que las poblaciones vivas se identificaran con esa referencia cultural y se reivindicaran de su continuidad. Aquí aparece el rol político del arqueólogo, quien se vuelve productor y promotor del patrimonio racial y material. El caso confirma así que la disciplina puede estar al servicio de un proyecto de soberanía. La representación continuista, que hace de la sincronía de niños, adultos y "abuelos", una diacronía filiativa de "abuelos", adultos y niños, donde la fetichización de los muertos permite el control de los vivos, 
favorece ampliamente la estructura productiva de la homogeneidad cultural. Como señaló tempranamente Bataille (2008) a propósito de la "estructura psicológica del fascismo", la producción de homogeneidad social requiere de un soberano que le sea heterogéneo, una soberanía que escapa a esa homogeneidad y la refuerza desde su exterioridad, este es el heterogéneo fascista que no se subsume en la totalidad homogénea que produce. Por otra parte, el gobierno de poblaciones (el disciplinamiento y la biopolítica del Centro para el Progreso) va a permitir que funcione el aparato que se aplica disciplinariamente sobre los niños que trabajan como operadores de la transformación. Por estos mecanismos se puede reproducir la forma continuista y homogénea que sustenta la heterogeneidad soberana.

La noción científica y religiosa de continuidad lineal y troncal que propone Le Paige le debe sin duda su inspiración a su principal maestro científico y espiritual, el filósofo y paleontólogo jesuita Teillard de Chardin. La antigüedad de los permanentes descubrimientos materiales en Atacama podían sumarse al gran programa místico de Teillard, intentando explicar el dinamismo físico y espiritual de los miles de años de vida de la humanidad desde el inicio de la "antropogénesis". En un manuscrito sin fecha, le Paige escribe:

"Estamos en la misma condicion que el Padre Teillard de Chardin [...] El teólogo quería que asignemos el momento que podemos decir 'este ser es ahora un ser humano'. La ciencia encuentra solamente un desarrollo lento, primeras pruebas de un trabajo de inteligencia rudimentaria, de un primer esfuerzo que poco a poco irá haciendo progresos [...] Qué concluir? Hacer confianza en la fe y en la ciencia siguiendo el sentimiento del mismo Padre Teillard de Chardin que juzgaba que nunca un descubrimiento científico puede servir de argumento contra la fe, como tampoco una creencia religiosa puede ser utilizada como arma contra el hallazgo del sabio".

En este argumento, y aplicando la búsqueda del primer humano a la del primer atacameño, la ciencia solo podrá probar la continuidad de una evolución, y la religión o la fe podrán decidir quién es humano o atacameño, es decir, operar una "máquina antropológica" (Agamben 2006). Pero es precisamente la fe atacameña en la potencia sobrehumana de los "abuelos" la que Le Paige enfrentó como desafío religioso, usando armas "científicas". Esta jerarquía entre una fe cristiana que supera la ciencia (en la dimensión de lo que el paleontólogo Teillard llamaba la "moral de cosmogénesis") y otra fe que no puede "ser utilizada como arma" contra la ciencia, es justamente la diferencia que sostiene la relación colonial que el misionero del Congo Belga reproduce en la Atacama chilena. Le Paige sustituye el tabú por el aura, la prohibición de contacto por la exhibición museal, produce el escenario de una pornografía científica que funciona como metáfora de la cadaverización de la etnia/raza, y a partir de esta transformación de espíritus de los muertos en cuerpos singularizados como "cosas-dioses" (Bazin 2008), produce la iconografía de una identidad nacional y étnica, insertándola en una red de "objetos en tránsito" al interior de un mercado suntuario de bienes arqueológicos. Todo lo cual no es menuda tarea, ya que coleccionar objetos y textos (producirlos o buscarlos en "eventos" de descubrimiento) se vuelve una "actividad política" (Fabian 2010) y económica. Como en el caso del etnógrafo africanista Marcel Griaule, la posición política del agente colonial lo lleva muchas veces a producir junto a sus discípulos un relato heroico del "descubrimiento" como hazaña de extracción o sustracción de los documentos de la cultura, y en una segunda etapa, al reconocimiento de una relación dialógica de coproducción de los documentos (Clifford 1998: 78-118). En el caso de Le Paige, esta relación dialógica no está nunca planteada en términos igualitarios con los "informantes nativos", en este caso niños y jóvenes, ya que se inscribe en la instauración de un patriarcado por parte de una autoridad religiosa institucional con "poderes" científicos. Viene entonces a constituirse la relación político-económica del patriarca con su tribu, produciendo una red de prestaciones y beneficios materiales que reproducen las relaciones de dependencia y subordinación a partir de la reproducción científica y religiosa de "lo indígena".

\section{* La gran exhibición y la consolidación COLONIAL REPUBLICANA}

Las cosas no solo siguen afectando a los que las poseen, sino también a todo un imaginario nacional que contribuye a aumentar el valor de las momias como cosas. La "reproducción mecánica de la imagen" (Benjamin 1991) permite expandir el alcance, el valor de exhibición, y la fosilidad (identidad) de las momias, incorporándola a la 
colección iconográfica de la soberanía colonial republicana. Como producto excedentario del objeto mismo, la imagen de las momias se multiplica en el espectáculo y el culto nacionalista. Al mismo tiempo, el aura del resto humano y su valor cultural adquieren una nueva historicidad en el marco de la disciplina arqueológica y de las narrativas etnohistóricas locales. Mientras que la imagen fotográfica contribuye a un historicismo decimonónico (Collingwood 2009), la cosa misma refuerza cierto valor de culto (el valor mágico religioso de los gentiles y el valor pornográfico de la exhibición museal). El mes de julio del año 1969 ofrece un hito de esta conjunción entre el régimen de exhibición y el culto nacionalista, una consumación del espectáculo arqueológico como rito fetichista, con la presentación de una exitosa exposición en la Casa Central de la Universidad Católica en Santiago, cubierta y comentada por casi todos los medios nacionales, y que atraerá a más de 4 mil visitantes por día. ${ }^{44}$ Aunque al principio se habría resistido a la propuesta, señalando que "El Museo es para que la gente vaya a verlo y no para andarlo mostrando", ${ }^{5}$ al final, Le Paige lo encontró "iFantástico! nunca pensé que vendría tanta gente". ${ }^{46}$ Es que efectivamente, ésta será la consagración mediática definitiva del misionero-arqueólogo como héroe nacional en Chile, quien aprovecha para desarrollar su campaña contra "el saqueo de tesoros inapreciables", alertando que "La protección a los lugares arqueológicos es urgente. Nadie hace nada hoy día y las autoridades son culpables", ${ }^{47}$ lo que viene a reforzar la idea que el cura, apoyado por los militares, sería la única garantía de protección de estas riquezas, al conservar el secreto de la localización de una caverna de petroglifos en Socompa: "No deseo que manos curiosas o profanas, sin conocimiento alguno sobre lo que significa esto para el progreso arqueológico chileno, causen destrozos irreparables, animados solo por un egoísta espíritu coleccionista o mercantil". ${ }^{8}$

En cuanto a la exhibición misma, ésta se componía de objetos datados entre 4.000 a 1.000 años AP, que do-

\footnotetext{
${ }^{44}$ La Segunda, "Le Paige nos trajo a nuestros abuelitos", 16/08/1969.

45 Revista Ercilla, "Le Paige: Pirquinero del pasado", por Fernando Barraza, 6/08/1969.

${ }^{46}$ Revista Vea, 14/08/1969.

${ }^{47}$ La Segunda, 16/08/1969.

${ }^{48}$ El Mercurio, "El Chile que duerme bajo la tierra", por Enrique Cid, $08 / 08 / 69$.
}

cumentan la prehistoria agrícola y metalúrgica, incluyendo colecciones de flechas y otras piedras talladas, instrumentos agrícolas, hachas de piedra, joyas, alfarería, objetos de oro, tres momias incluyendo la famosa Miss Chile (1958) y un niño con el "único ejemplar en el mundo de un aparato reducidor de cráneos", bloques de plomo usados como moneda de cambio, mazorcas, y también libros de registros de bautismo de la parroquia de Chiu Chiu del siglo XVII. Todo este material fue acarreado en camión por el propio Le Paige, en un viaje de tres días junto al joven Juan Salva de 15 años, en 14 baúles que, según el misionero, eran "la cincuentava parte de lo que hay allá. Traje dos docenas de cántaros negros y tengo 2.500. Acá hay solo tres momias y tengo 225 ". ${ }^{49}$ Lo que la prensa consideró como "un resumen completo de la historia del hombre". Adicionalmente a la muestra, el evento incluía la presentación de 100 "chinos" de la Federación de bailes religiosos de La Tirana, incluyendo 19 promeseros por bailes como "gitanos", "chunchos", "pieles rojas", "danza numero 1" junto a 23 músicos..$^{\circ} \mathrm{El}$ escritor del Norte Grande Andrés Sabella también daría conferencias, junto a las de Le Paige sobre "La cultura agro-alfarera de Atacama".

Entre las ideas de Le Paige más comentadas por la prensa con ocasión de la gran exposición, estaba la antigüedad de la ocupación de Atacama, que al primer día de la exposición es de 30.000 años $\mathrm{AC}$, y hacia el final ya va en 70 mil, y se difunde que los atacameños "son descendientes del Hombre de Pekín que vivió hace 350.000 años". ${ }^{51}$ También se afirma como verdad comprobada, la continuidad cultural milenaria de la cultura atacameña, para lo cual los objetos ayudan a la "revelación instantánea de que el hombre ha permanecido siempre bajo una esencia inmutable". ${ }^{2}$ Esta idea convivirá en el imaginario, sin contradicción, con otra idea, la de: "Una explosión o lluvia radioactiva [que] habría exterminado a los atacameños y devastado la zona dejándola cubierta de salitre haciendo desaparecer a estos hombres que vivieron hace 30.000 años... De aquellos hombres no hay más vestigios fósiles que una mandíbula". ${ }^{3}$

\footnotetext{
${ }^{49}$ Revista Vea, 14/08/1969.

${ }^{50}$ La Segunda, 16/08/1969.

${ }^{11}$ El Siglo, "Arqueología nortina muestra sacerdote Gustav Le Paige en la U. Católica", 6/08/1969.

${ }^{52}$ La Nación, "Exposición atacameña", por P. T., 9/08/1969.

53 El Siglo, "Arqueología nortina muestra sacerdote Gustav Le Paige
} 
Sin duda que todo esto resultaba fascinante y misterioso para el gran público santiaguino, que podía sentir que estaba accediendo a los conocimientos más avanzados sobre su propio origen, aunque más bien, se puede considerar que se estaba en ese momento produciendo la apropiación imaginaria de un territorio y una historia que antes les resultaban ajenos. La operación museológica permitía así la constitución del origen y la colonización del espacio y el tiempo del desierto como una propiedad, y al constituirlos como propiedad, definir la nación como dueña y heredera. Le Paige le estaba entregando a los chilenos el placer de la conquista, y activando el deseo del origen, por medio de la exhibición de los objetos que vendrían a constituirse en íconos nacionales. En esta historia, al instalarse como intermediario entre los "abuelos" atacameños y los habitantes vivos de Atacama, éstos se vuelven sus hijos; por un mecanismo homeostático, desaparecían siglos de violencia colonial de los registros históricos. Del neolítico se saltaba directamente al advenimiento casi mesiánico y decididamente patriarcal del cura Le Paige, quien engendra la herencia de la "cultura atacameña", y al pueblo atacameño como una nueva prole del imaginario nacional. Un narrador de este imaginario, Andrés Sabella, escribirá precisamente, "el padre Le Paige... vivió en medio de muertos que le 'hablaban'. Ahora, no es un muerto más: es el más vivo de los hombres del mundo atacameño que le fascinó" (1980). De hecho, la exposición fue también la ocasión de dar a conocer que todo su trabajo lo había hecho con dos niños, que lo habían acompañado por once años. El mismo Le Paige tenía cierta afición por producir su propia leyenda como "descubridor de la cultura atacameña", ${ }^{44}$ señalando "la providencia" como su principal recurso de investigación, seguida de la Universidad del Norte y de "dos muchachos de mi pueblo, Eulogio Cervantes y Manuel Abán López. A pesar de que tienen cuarto año primario son especialistas".55

El impacto nacional de esta exhibición dirigida al público capitalino, muestra solo una cara de la política museológica de Le Paige, que según los antecedentes que

en la U. Católica", 6/08/1969. Destacado nuestro.

${ }^{54}$ El Siglo, "El padre Le Paige", 7/08/1969.

55 Las Últimas Noticias, "Padre Le Paige: Los turistas son una plaga", 6/08/1969. siguen, estaba igualmente orientada a la escena de los museos europeos, en continuidad con el sentido colonial y monárquico que le dio a su relación científica y museográfica con el Museo de Tervuren. Desde el inicio de sus investigaciones en Atacama, era una práctica común de Le Paige regalarle objetos encontrados a sus visitantes más ilustres o "respetables", más aún si estos mostraban interés en las antigüedades americanas, como era el caso de monseñor Campagner que viajó por América juntando los objetos que componen hoy la colección Campagner del Museo de Trevisi. A este obispo italiano Le Paige habría regalado a finales de los años cincuenta una importante colección de parafernalia chamánica (Laurencich y Colella 2008).

A principios de los sesenta, habiendo ya excavado decenas de cementerios y cientos de tumbas, Le Paige envía al Musée de l'Homme de Paris, una importante donación de 190 piezas provenientes de los sitios de Gatchi, Tulan, Ascotan, Tambillo, San Pedro de Atacama, Solor y Coyo, incluyendo proyectiles, instrumentos líticos de corte y uso agrícola, collares de malaquita y turquesa, jarros de cerámica negra y roja..$^{56} \mathrm{La}$ donación será hecha por intermedio del espeleólogo francés Haroun Tazzief, quien andaba en Chile estudiando la erupción del volcán Calbuco. $\mathrm{Al}$ año siguiente, vuelve a enviar una nueva colección al Musée de l'Homme, de 36 piezas provenientes de Gatchi, Tulan y San Pedro, principalmente instrumentos líticos, collares extraídos de tumbas, y textiles de lana portados por momias, donación esta vez efectuada por un cierto coronel Castex. ${ }^{57}$ En 1970, con ocasión de la entrega de la Medalla al recibir la Orden de la Corona Real de Bélgica, el embajador de Bélgica en Chile, Franz Taelemans queda muy interesado por una conversación confidencial en la que Le Paige le había señalado "sus intenciones de legar al Museo de Tervuren una parte aún no especificada de su colección de arqueología", a lo cual el embajador le responde después de averiguaciones, que las autoridades belgas están de acuerdo y que gestionará los permisos ante las autoridades chilenas. ${ }^{58}$ Esta intención de gran relevancia política puede haber sido descartada, al año

\footnotetext{
${ }^{56}$ Inventario Sección Americanista, Musée du Quai Branly (ex Musée de l'Homme), París, marzo de 1961.

57 Inventario Sección Americanista, Musée du Quai Branly (ex Musée de l'Homme), París, julio de 1962.

${ }^{58}$ Embajador F. Taelemans a G. Le Paige, Santiago, 28/07/1970. Archivo IIAM, San Pedro de Atacama.
} 
siguiente, con la nacionalización por gracia que Salvador Allende le otorga a Gustavo Le Paige. Poco después (nov. 71), luego de una visita a San Pedro, el director de la Escuela Militar de Santiago le solicita "algunas piezas" para la sala antigua del museo histórico de la escuela, que quiere ser "un eslabón más de conocimientos de la Historia, Geografía y tradiciones de nuestra Patria".59 Entre tanto, los atacameños elaboraban sus propias lecturas de este tráfico de objetos. Benigno Salinas, por ejemplo, vincula directamente las prácticas arqueológicas con las expropiaciones de los conquistadores españoles:

"[Le Paige] Iba a buscar... ehh, allá en Toconao no se metía él en el cementerio. Yyo creo que, yo después pensando, estos robaron mucho por allá por el Perú poh. Si eran puros gallos malos los que venían ahí con los españoles poh. Malos los gallos. Entonces robaron y cuestiones y a las finales trataron con el oro, y el Padre Le Paige se lo llevó, y después trajo al rey poh, pa que llevara... trajo los reyes poh. Entonces a los reyes en la aduana no los revisaron... Se llevaron todo el oro poh. Si a eso los llamó poh. [iPero por qué la gente le pasa las cosas al padre, le pasaba todo?] Es que... siempre es tímida la gente de allá poh. Tímida"."

\section{* Indigenismo militar y colonialismo FRONTERIZO}

La afinidad militar de la museografía atacameña tendrá sin embargo su apogeo, como no, después del golpe de estado de Augusto Pinochet y la Junta de Gobierno. Al año del golpe, mientras Le Paige publicaba la Guía del Museo Arqueológico, Sergio Nuño, embajador de Chile en Bélgica, le solicita a Le Paige defender "la posición de Chile" ante la adversa campaña internacional contra el régimen militar, ${ }^{61} \mathrm{y}$ al año siguiente, le ofrece organizar conferencias "sin que aparezca la participación de la embajada para que no lo confundan con una finalidad política". ${ }^{62}$ Poco después están apareciendo noticias sobre Le Paige en el diario Le Soir de Bruselas, y Nuño le

\footnotetext{
59 Coronel A. Labbé a G. Le Paige, Las Condes, 23/11/1971. Archivo IIAM, San Pedro de Atacama.

${ }^{60}$ Entrevista a Benigno Salinas, atacameño de Toconao, jubilado de Chuquicamata, 2010.

${ }^{61}$ S. Nuño a G. Le Paige, Bruselas, 20/11/1974. Archivo IIAM, San Pedro de Atacama.

${ }^{62}$ S. Nuño a G. Le Paige, Bruselas, 17/09/1975. Archivo IIAM, San Pedro de Atacama.
}

escribe "no sabe cuánto me ha alegrado y sirve a nuestro Chile que aparezcan artículos de índole cultural que disipen en algo la tremenda y muy bien organizada y financiada campaña que se lleva contra nuestro Gobierno", y aprovecha de solicitarle apoyo para su hijo que tiene que filmar un reportaje sobre el ferrocarril Antofagasta-Bolivia para la BBC. ${ }^{63}$

Pero el momento quizás más significativo de instalación del patrimonio arqueológico atacameño en un museo colonial europeo, es el de la expedición al Museo de América de Madrid, encomendada por Pinochet y la junta militar, en un gesto de fortalecimiento de las relaciones culturales con la España fascista de Franco. ${ }^{64}$ Aunque programado para el año 75 , el viaje de Le Paige junto a las colecciones fue interrumpido por una enfermedad que lo obligó a hospitalizarse en Santiago. Manuel Corante se acuerda así del episodio: "La gente se espantó... se iba a embarcar a su país, Bélgica, con lo que llevaba de acá, y llegó enfermo a Tacna... Se espantaron iporqué se está llevando la riqueza del pueblo?, pero no le dijeron, na mas que comentaban así". ${ }^{65} \mathrm{La}$ expedición se concretó en 1976, bajo el patrocinio de la Universidad del Norte; el padre Le Paige viajó acompañado del rector delegado, coronel (r) Hernán Danyau Quintana. La colección fue presentada al almirante José Toribio Merino en Santiago, y siguió rumbo al Museo de América, donde llegó justo un día antes de la inauguración de la Sala Chile. La donación se componía de 201 piezas provenientes de los tres museos de la Universidad del Norte (San Pedro de Atacama, San Miguel de Azapa y Regional de Iquique-Centro Isluga), de las cuales 84 provenientes de San Pedro, incluyendo instrumentos líticos y metálicos, cerámica negra y roja, cestería, textiles, tabletas, huesos y cráneo con gorro. ${ }^{66}$ Hasta Madrid llegaron no solo tres momias atacame-

\footnotetext{
${ }^{63}$ S. Nuño a G. Le Paige, Bruselas, 2/10/1975. Archivo IIAM, San Pedro de Atacama.

${ }^{64}$ Viaje realizado a Europa por el rector de la Universidad del Norte, coronel (r) Hernán Danyau Q., del 2 al 27 de mayo 1976 acompañado del Padro Gustavo Le Paige, director del Museo Arqueológico de San Pedro de Atacama y de don Miguel Campo Rodríguez, director general de Asistencia Técnica Internacional, junio de 1976, Universidad del Norte.

${ }^{65}$ Entrevista a Manuel Corante, por H. Gundermann, 1998.

${ }^{66}$ Colección de objetos antropológicos, arqueológicos y artesanales cedidos por la Universidad del Norte, de Chile, al Museo de América, de Madrid; curadora Mercedes Palau, 1977. Museo de América, Madrid.
} 
ñas (un adulto y dos niños), sino también las afecciones propias de los "abuelos": dos museógrafas encargadas de instalar la muestra adquirieron la Enfermedad de Ménière durante la instalación de las momias, que se habían venido descomponiendo en los tres meses de viaje. ${ }^{67} \mathrm{Y}$ mientras se preparaba este viaje, el agregado cultural de Chile en Estados Unidos invita al sacerdote de San Pedro junto a "una muestra importante y valiosa”, en una propuesta ya conversada con el vicerrector de la Universidad del Norte, el doctor Alfredo Cea Egaña y el ex rector Gerardo Claps. ${ }^{68}$ El mismo Le Paige le escribe a su hermano su cercanía con el proyecto diplomático-cultural de los militares: "Es el gobierno actual, con toda razón, [que] busca embajadores de paz, de concordia, de ciencia y de nada más". 99 Paz y concordia con los pocos países que apoyaron la dictadura chilena, España y Estados Unidos, cuando los militares pasaban por las armas toda oposición política.

Aunque hasta aquí parece llegar la práctica de "exportación” por donación del patrimonio arqueológico de Atacama, y el rol de Le Paige como embajador cultural de la dictadura militar, seguirán sin embargo sus actividades de difusión de culturas precolombinas, prehistoria de San Pedro y ciencia arqueológica: conferencias en División Salvador de Codelco, (mayo 77), exposiciones "Joyas precolombinas" (76) y "Tabletas de rapé” (4/13/77) en la Galería de Enrico Bucci de Santiago, y se obtendrán los recursos para la construcción y ampliación del museo (Le Paige y Núñez 1977: 157-158). Toda esta actividad de agente y embajador cultural en dictadura se verá coronada por la visita de Augusto Pinochet y su esposa Lucía Hiriart al Museo de San Pedro de Atacama, intensamente documentada por los servicios de prensa del gobierno militar y los periódicos nacionales, que dan extensa difusión a los discursos y momentos de la visita.

Arribada en helicóptero desde Calama, dos mil personas reciben a la pareja presidencial en la plaza de San

\footnotetext{
${ }^{67}$ Según Carmen Cerezo, que nos contó esta historia donde participó junto a la curadora Mercedes Palau y la museógrafa Chica Mantilla, las momias siguen hoy en estado de descomposición en las bodegas del Museo de América. Com. pers., Madrid, 25 de mayo del 2010.

${ }^{68}$ Mario Correa a G. Le Paige, Washington D.C., 10/02/1976.

${ }^{69}$ G. Le Paige a Constantin Le Paige, 6/05/1976 (Du Brulle 2010: 133).
}

Pedro, donde se inician los discursos. El primero en hablar es Humberto Cruz, el presidente de la Junta de Vecinos, quien señala "como hombres y mujeres chilenos de los pueblos cordilleranos, damos gracias a Ud. Señor Presidente por sus esfuerzos para hacer este país grande, próspero y feliz". Luego hablaría Gustavo Le Paige, presentado por la prensa como "el dueño del pueblo",70 para dar la bienvenida a la "cuna de la patria chilena", desde donde partió Pedro de Valdivia, y se encuentra la capilla más antigua de Chile, mostrando que "somos los primeros chilenos". Y hace un voto para el general: "Que Dios le entregue una vida larga y largos años en el poder para hacer de Chile una patria feliz".71 Ante lo cual, "Brazos en alto y banderas nacionales, y gritos de apoyo testimoniaron su apego a la tierra chilena". Como se puede apreciar en el tono de los discursos, la visita de Pinochet activa todo un sistema de prestaciones y contraprestaciones clientelares donde se reafirman las jerarquías de la dominación personal entre un soberano y sus súbditos, entre un soberano grande, y uno pequeño. Mientras Le Paige le obsequia a Pinochet y esposa "dos cántaros negros pulidos de la segunda fase de la cultura atacameña" (hallados en Solor y datados ca. 1700 AP), las socias del Centro de Madres le regalan a Lucía Hiriart "ponchos, tejidos de llamo", para que luego ella elija tres ponchos más. Pero estos regalos van junto a demandas: mientras que en la plaza le habían solicitado a Pinochet la extensión de la red de televisión hasta San Pedro, según la prensa "único medio de distracción para estos habitantes", inaugurado en Taltal el día enterior, ${ }^{72}$ las socias artesanas de CEMA le piden a la señora Lucía que esta nueva red llegue hasta Toconao. ${ }^{73}$ En el momento, Pinochet ofrece algunas regalías. La más celebrada por la prensa será la del discurso de recepción: "voy a disponer un incremento de los operativos cívico-militares a fin de prestar el apoyo que necesiten los habitantes de

\footnotetext{
${ }^{70}$ La Tercera, "Presidente visitó cuna de la patria: San Pedro de Atacama”, 10/04/1977.

${ }^{71}$ El Mercurio, "Este gobierno no promete sino que realiza cosas", 10/04/1977. La versión de Las Últimas Noticias, 10/04/1977: "somos chilenos que le deseamos que Dios le entregue larga vida y muchos años en el poder para que Chile sea reconocido en el extranjero como una gran nación".

${ }^{72}$ ElMercurio, 10/04/1977.

${ }^{73}$ Las Últimas Noticias, "Ayuda especial a San Pedro de Atacama dispuso Primer Mandatario", 10/04/1977.
} 


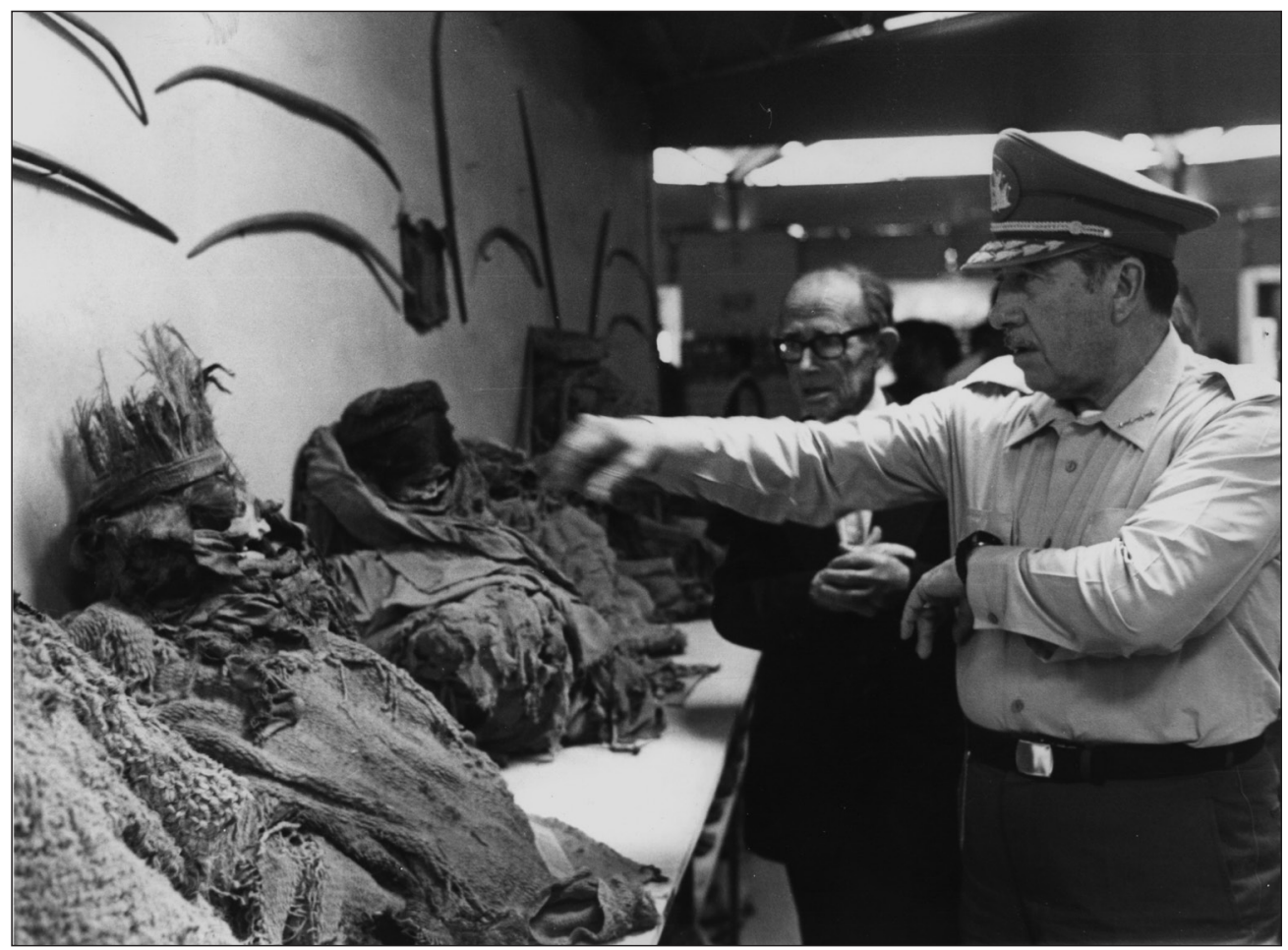

Figura 14. Augusto Pinochet y Gustavo Le Paige observando las momias. 1977. Archivo IIAM.

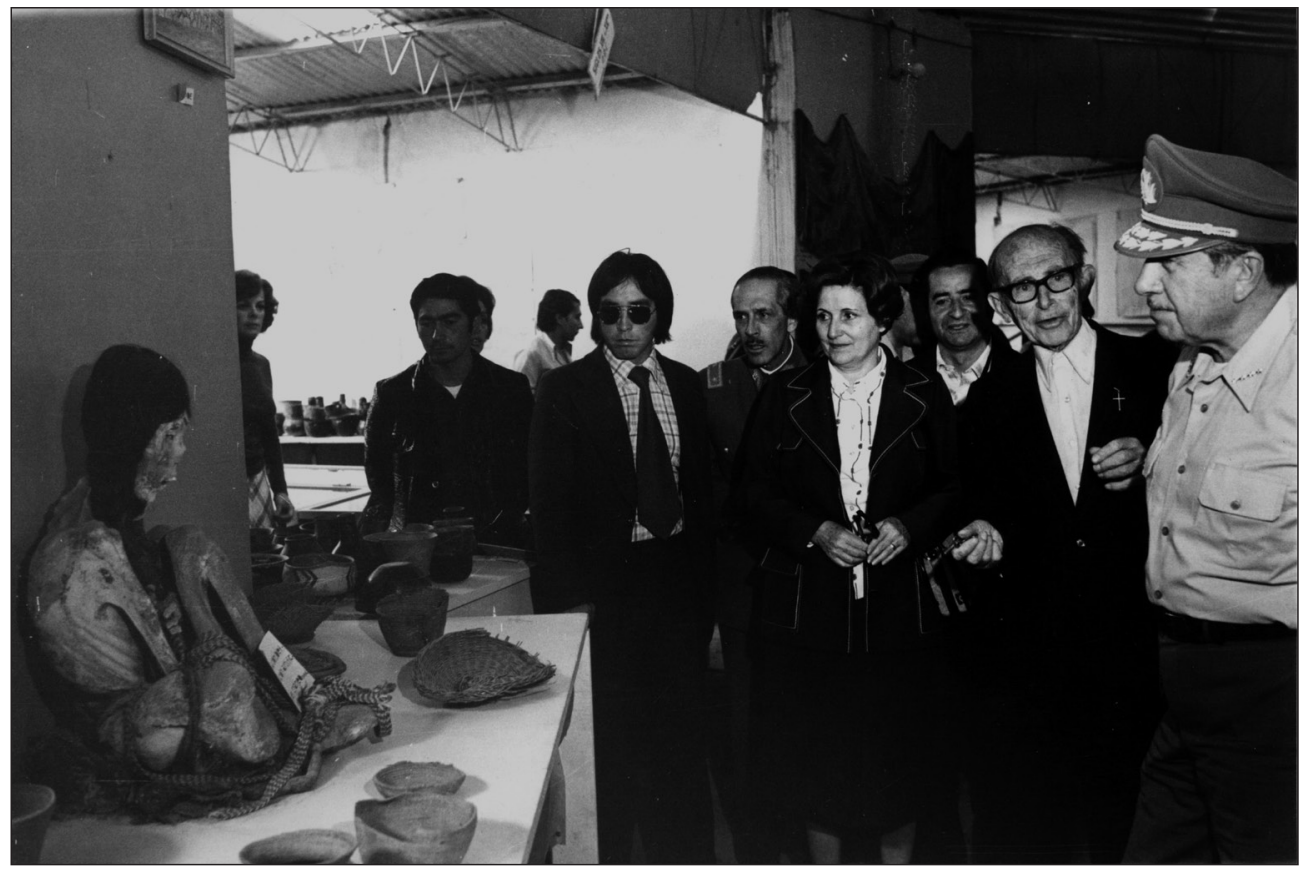

Figura 15. Augusto Pinochet, Gustavo Le Paige, Lucía Hiriart de Pinochet y un guardaespaldas observando la momia conocida como Miss Chile. 1977. Archivo IIAM. 
San Pedro".74 Luego del recorrido oficial por el museo (Figuras 14 y 15), Le Paige declarará: "Recibí un aporte fiscal para terminar la tercera sección del museo y con posibilidades para iniciar la cuarta", ante lo cual El Mercurio precisa que se trata de un museo con "50.000 años de historia".75 La administración militar también seguirá solicitando (ia cambio?) su colaboración, a quien parece haber considerado como un aliado en la política de seguridad interior del Estado y ejercicio de la soberanía en los territorios fronterizos. Así, el mismo mes de la visita presidencial el superintendente de Educación solicita a Le Paige información sobre los "grupos humanos" "aymaráes" (sic) de la segunda región para el Plan de Desarrollo Integral Fronterizo. ${ }^{76}$

$\mathrm{Al}$ año siguiente de la visita de Pinochet, se edita el volumen de la colección Patrimonio Cultural del Ministerio de Educación, sobre Cultura atacameña (1978), que presenta el estado del arte de la arqueología del momento, con una notoria invisibilización de los indígenas "vivos". No sabemos sin embargo a qué se podría parecer un "indígena del Desierto de Chile" (Mege 2009) sino a un chileno, a diferencia del indígena araucano cuya imagen sabemos ha sido producida como significante indígena por los mismos fotógrafos chilenos y extranjeros. En ambos casos, es la cultura material que viste o re-viste al indígena de indigenidad, por lo que la búsqueda de "indígenas de Chile" está condenada a encontrar artificios propios de la mirada colonial chilena. Mientras que con el araucano, el cuerpo del indígena es vestido de manta y trarilonko para parecer indígena, con el atacameño, es el cadáver del cuerpo que viene vestido como indígena. La momia es un cliché, un registro corporal anterior a la fotografía y todos sus montajes indigenistas, un indígena anterior a esa máquina de representación. La momia

${ }^{74}$ La Tercera, 10/04/1977.

75 El Mercurio, 10/04/1977. Poco después, Le Paige le escribe al general Pinochet solicitando apoyo para financiar el núm. 6 de la revista Estudios Atacameños, "considerando su alto espíritu y nuestro aprecio mutuo le entrego el índice de la revista y su presupuesto para ver que puede hacer Ud. por nosotros" (G. Le Paige a A. Pinochet, San Pedro de Atacama, 27/03/1978, Archivo IIAM-UCN). Al dictador parece haberle gustado el índice ya que el financiamiento del número finalmente se concretó (Le Paige 1978: 4).

${ }^{76}$ Capitán (M) Eduardo Cabezón, Superintendente de Educación Pública, a Le Paige, Santiago, 28/04/1977, Ord. 429, Mat: "Solicita información escrita sobre comunidades aymaráes". connota la derrota del área cultural que ningún indígena vivo puede aspirar a representar; esta derrota se consuma desde el momento mismo en que el etnólogo aspira a representar la cultura como área o reducto, es decir, desde que la vida indígena se ve reducida a la representación etnológica (disciplinaria) vaciada de toda soberanía (Pavez 2005). Allí, en el espacio desértico de la derrota, aparece Le Paige para instalar a los muertos como representantes de los vivos, y a sí mismo como representante de los muertos.

Para terminar, recordemos el discurso del rector de la Universidad del Norte, Jaime Oviedo Cavada, cuando le entrega a Le Paige la Encomienda de la Orden Isabel La Católica: "En estos oasis atacameños... se asentó el hispano y se inició el largo proceso de trasculturación con las etnias indígenas... La acción de los sacerdotes que tuvieron a su cargo la doctrina de San Pedro de Atacama y de Chiu Chiu... aportó al indígena un nuevo concepto religioso que fue bien recibido y aceptado"..$^{77}$ Ante lo cual, el sacerdote responde "aquí en el desierto encontré la Providencia". Le Paige participa de este blanqueamiento de la acción evangelizadora, transformando la presencia sacerdotal en una forma de soberanía auratizada por la "Providencia". Una providencia que también habría actuado junto a los militares cuando el golpe de Estado de 1973:

"Hoy día fiesta nacional chilena. Todo está muy tranquilo y cerca de normalizarse en todos los ámbitos. Desgraciadamente, la prensa extranjera se permite de decir tonteras y más tonteras! Ya que la oposición no puede hacerlo aquí! Gracias a Dios Chile podrá retomar su restauración social y económica... Solo en unos años más podremos darnos cuenta de las razones por las cuales la Providencia permitió que Chile sea bien sacudido por una vez en su vida... todo está tranquilo de nuestro lado de la Cordillera: y que no vengan a revolverla!"? ${ }^{8}$

Se ha señalado a Le Paige como "hombre de su tiempo". Esta expresión supone que el tiempo no dio posibilidades de ser de otra forma, olvidando que incluso en los tiempos oscuros, tiempos coloniales o tiempos de represión, algunos hombres lucharon contra la tiranía. Le

\footnotetext{
77 “Embajador de España condecoró a Le Paige", 2/12/1977.

${ }^{78}$ G. Le Paige a Constantin Le Paige, 18/12/1973 (Du Brulle 2010: 131-132).
} 
Paige en cambio la celebró. También se ha dicho que San Pedro de Atacama no sería lo que es hoy día sin él. Esto también es discutible: otros observadores ya veían en los años cincuenta el potencial turístico del lugar (Rudolf 1951), así como su calidad de "reserva" arqueológica (Latcham 1938). En cuanto al Museo Arqueológico, como todos los museos coloniales, está marcado como producto de una patrimonialización expropiatoria y de las prácticas autoritarias que han determinado la relación entre las instituciones nacionales y los habitantes de San Pedro de Atacama. Habrá que ver si el peso de la figura fundadora en el imaginario regional, eclesiástico y universitario, seguirá constituyendo un obstáculo para el cumplimiento institucional de los convenios internacionales (OIT, ICOMOS) sobre reparaciones a los pueblos colonizados, y devolución de colecciones materiales y restos humanos, a las que aspira el movimiento atacameño contemporáneo. Por mientras, el Museo sobrevive a su mayor paradoja: el estar enclavado en un territorio indígena lo vuelve objeto del deseo indígena de ejercer soberanía sobre lo que le fue sustraído en nombre de la disciplina arqueológica. Un "gentilar" que divide a los atacameños entre los que creen en la plusvalía del patrimonio y los que creen en la potencia de "las costumbres", aquellas que indican que los "gentiles" deben volver bajo tierra. El soberano Le Paige, hoy convertido en un "gen- til" más, sigue así ejerciendo el poder acumulado en su museo-chullpa.

Agradecimientos En esta investigación he contado con el apoyo de numerosas personas. En San Pedro de Atacama, agradezco especialmente a Gilles Rahier, Manuel Arturo Torres, Héctor Ramírez, Santiago Ramos, Cristina Garrido, Ulises Cárdenas, Valentina Figueroa, Hans Gundermann, Lautaro Núñez, Larissa de Ruyt, y por supuesto, Lilith Kraushaar. También a Julio Vezub y Diego Escolar por invitarme a presentar los esbozos de este trabajo en el Simposio "Los archivos antropológicos de la nación: escrituras, cuerpos, artefactos y museos" en el VII Congreso Chileno de Antropología en San Pedro de Atacama (25-29 de octubre 2010). A Paz Núñez-Regueiro del Musée du Quai Branly (Paris, Francia), Julien Volper y Marteen Coutenier del Musée Royal d'Afrique Centrale (Tervuren, Bélgica), Sergio Arce de la Biblioteca Central de la Universidad Católica del Norte (Antofagasta, Chile), y Carmen Cerezo del Museo de América (Madrid, España), por facilitarme documentos e informaciones valiosas. Finalmente, señalar que la investigación de las colecciones en Europa fue posible por el apoyo del proyecto ECOS-CONICYT CogHor "Formas del colonialismo republicano en el Cono Sur", dirigido por Luc Capdevilla y Rolf Foerster.

\section{* Referencias citadas}

\section{Fuentes inéditas}

Archivo de Donaciones, Sección Americanista, Musée du Quai Branly, París, Francia.

Archivo de Gustavo Le Paige, Biblioteca y Centro de Documentación, IIAM, Universidad Católica del Norte, San Pedro de Atacama.

Archivo de Hans Gundermann K., IIAM, Universidad Católica del Norte, San Pedro de Atacama.

Archivo de la Provincia de la Compañía de Jesús, Santiago de Chile.

Archivo de la Sección Etnográfica, Musée Royal d’Afrique Centrale, Tervuren, Bélgica.

Centro Multimedia, Biblioteca Central de la Universidad Católica del Norte, Antofagasta.

AGAMBEN, G., 2002 [1978]. Le pays des jouets. Refléxions sur l'histoire et sur le jeu. En Enfance et histoire. Destruction de l'expérience et origine de l'histoire, G. Agamen, pp. 123-157. Payot, Paris.

2006. Lo abierto. El hombre y el animal. Adriana Hidalgo editora, Buenos Aires.

AYALA, P., 2007. Relaciones entre atacameños, arqueólogos y Estado en Atacama (norte de Chile). Estudios Atacameños 33: 133-157.

2008. Políticas del pasado. Arqueólogos, indígenas y Estado. QILLQA-IIAM, Universidad Católica del Norte, San Pedro de Atacama.

BATAILLE, G., 2008. La estructura psicológica del fascismo. En La conjuración sagrada. Ensayos 1929-1939, G. Bataille, pp. 137-180. Adriana Hidalgo editora, Buenos Aires. 
BAZIN, J., 2008. Des clous dans la Joconde. L'anthropologie autrement. Anacharsis, Toulouse.

BENGOA, J. (Comp.), 2004. La memoria olvidada. Historia de los pueblos indígenas de Chile. Publicaciones del Bicentenario, Presidencia de la República, Santiago de Chile.

BENJAMIN, W., 1991. L'oeuvre d'art a l'époque de sa reproduction mécanisée. En Ecrits français, Walter Benjamin, pp. 177-250. Folio, París.

BENNET, T., 1995. The Birth of the Museum. History, theory, politics. Routledge, London y New York.

BITTMAN, B., G. LE PAIGE y L. NÚÑEZ, 1978. Cultura atacameña. Serie Patrimonio cultural chileno. Departamento de Extensión Cultural del Ministerio de Educación, Santiago de Chile.

CEE - Centre d'Etudes Ethnologiques, 1968. Dieu, idoles et sorcellerie dans la région Kwango/Bas-Kwilu. Rapports et compte-rendus de la IIème semaine d'études ethno-pastorales 1966. Publications du Centre d'Etudes Ethnologiques, Bandundu (Congo).

1969. Mort, funérailles, deuil et culte des ancètres chez les populations du Kwango/Bas-Kwilu. Rapports et compte-rendus de la IIIeme semaine d'études ethno-pastorales 1967. Publications du Centre d'Etudes Ethnologiques, Bandundu (Congo).

CÁRDENAS, U., 2001 Ms. Percepciones de las comunidades atacameñas sobre el tratamiento del patrimonio cultural de la zona. Ms. inédito. $18 \mathrm{pp}$.

CASTRO, V., 2009. De ídolos a santos. Evangelización y religión andina en los Andes del Sur. Dibam y F. Americanista Universidad de Chile. Edición de Huacca Muchay, Universidad de Chile (1997), Santiago de Chile.

CLIFFORD, J., 1995. Dilemas de la cultura. Antropología, literatura y arte en la perspectiva posmoderna. Paidós, Buenos Aires.

COLAS, M., 1938. Ou les chef-d'oeuvres naissent comme le chant.../ Fétiches. Revue de l'Aucam 13 (2): 76-77 y 99-101.

COLLINGWOOD-SELBY, E., 2009. El filo fotográfico de la historia. Walter Benjamin y el olvido de lo inolvidable. Metales Pesados, Santiago de Chile.

CORANTE, M., y L. GONZÁLEZ, 2008. Historias que contar: las andanzas de un atacameño. Edición del autor, San Pedro de Atacama.

CORBEY, R., 2000. Tribal Art Traffic. A Chronicle of Taste, Trade and Desire in Colonial and Post-Colonial Times. Royal Tropical Institute, Amsterdam.
COUTENIER, M., 2004. Fysieke Antropologie, Koloniale Etnografie en Het Museum van Tervuren. Een Geschiedenis van de Belgische antropologie (1882-1925). Tesis de doctorado en antropología social y cultural, Katholieke Universiteit Leuven, Louvain.

DU BRULLE, C., 2010. Le dernier roi de l'Atacama. Mols, Bruxelles.

ERHARDT, H., 1998. Max Uhle en Chile (1912-1919). Sus aportes pioneros al estudio del Precerámico costeño. Indiana 15: 107-138.

ESCOLAR, D., 2007. Los dones étnicos de la Nación. Identidades huarpe y modos de producción de soberanía en Argentina. Prometeo Libros, Buenos Aires.

ESPOSITO, R., 2007. Communitas. Origen y destino de la comunidad. Amorrortu, Buenos Aires.

FABIAN, J., 2006 [1983]. Le temps et les autres. Comment l'anthropologie construit son objet. Anacharsis, Paris.

2010. Colecionando pensamentos: sobre os atos de colecionar. Maná 16 (1): 59-73.

FABIANI, J.-L., 2005. Faire école en sciences sociales: un point de vue sociologique. Cahiers du Centre de recherches historiques 36: 191-207.

FOERSTER, R., 1996. Jesuitas y mapuches. Editorial Universitaria, Santiago de Chile.

2011. "La Compañía Explotadora v/s el Obispo Edwards y sus archivos fotográficos, la Armada y su archivo naval. Una aproximación al colonialismo en Rapanui". En La Compañia Explotadora de Isla de Pascua. Patrimonio, Memoria e Identidad en Rapa Nui, M. Fuentes y N. Castro (Eds.), pp. 121-134. Editorial Escaparate, Santiago de Chile.

FOERSTER, R., y J. VEZUB, 2011. Malón, ración y nación en las Pampas: el factor Juan Manuel de Rosas (1820-1880). Historia (Santiago) 44 (2): 259-286.

FOUCAUlT, M., 200o. Defender la sociedad. Curso en el Collège de France (1975-1976), Fondo de Cultura Económica, Buenos Aires.

GÄNGER, S., 2010. The Collecting and Study of Pre-Hispanic Remains in Peru and Chile, ca. 1830s-1910s. Ph.D. Dissertation in History, University of Cambridge.

HOUBEN, R. P., 1929. La migration chez le noir: obstacle à l'évangélisation.

HUbBE, M., M. OVIEDO y C. TORRES-ROUFF, 2011. El estado de conservación de la colección osteológica Gustavo Le Paige y su contextualización cronológica. Estudios Atacameños 41: 29-44. 
HURTADO, A., 1936. La crisis sacerdotal en Chile. Splendor, Santiago de Chile.

1941. ¿Es Chile un país católico? Splendor, Santiago de Chile. Reed. Cámara Chilena de la Construcción/ Biblioteca Nacional/ Universidad Católica de Chile, 2009.

JEWSIEWICKI, B., 1991. Peintres de cases, imagiers et savants populaires du Congo, 1900-1960. Un essai d'histoire de l'esthétique indigene. Cahiers d'études africaines 31 (123):307-326.

LATCHAM, R., 1938. Arqueología de la región atacameña. Prensas de la Universidad de Chile, Santiago de Chile.

LAURENCICH MINELLI, L., y M. COLELLA, 2008. Collezione Precolombina Campagner. Il Volo Sciamanico, vol. I., Museo del Seminario Vescoville, Treviso.

LE PAIGE, G., 1935. L'art et la statuaire au Congo. Revue Missionaire des Jésuites Belges 9: 245-248.

1944. Yasa. A la croisée des routes de l'exode. Ms. 600 folios, 250 mapas.

1945 Ms. Art indigène chrétien au Kwango. Manuscrito. 11 folios.

1949. L'art chrétien en Afrique Centrale. Revue du Clergé africain $4(6): 445-452$.

1957-1958. Antiguas culturas atacameñas en la cordillera chilena. Anales de la Universidad Católica de Valparaíso 4-5: 15144 .

1961. Cultura de Tiahuanaco en San Pedro de Atacama. Anales de la Universidad del Norte 1 (1): 17-110.

1963. Continuidad o discontinuidad de la Cultura Atacameña. Anales de la Universidad del Norte: Congreso Internacional de Arqueología de San Pedro de Atacama (6-13 de enero 1963) 2: 7-28.

1964. El precerámico en la cordillera atacameña y los cementerios del período agro-alfarero de San Pedro de Atacama. Anales de la Universidad del Norte 3: 5-275, incluye 160 láminas.

1965. San Pedro de Atacama y su zona (14 temas). Anales de la Universidad del Norte 4:5-29, más 66 láminas.

1966. Cráneos atacameños. Evolución. Ritos. Anales de la Universidad del Norte 5: 7-10, más 37 láminas (pp. 11-82).

1973. El valor arqueológico del Museo San Pedro de Atacama. Estudios Atacameños 1: 7-20. 1974a. Guía del Museo de Arqueología. Universidad del Norte, San Pedro de Atacama.

1974b. El yacimiento de Tchaputchayna. Estudios Atacameños 2: $59-74$

1974c. Editorial/Informes de trabajo/ Noticias. Estudios Atacameños 2: 3-6 y 101-110

1975a. Editorial/ Noticias/Comentarios. Estudios Atacameños 3: 3-4, 107-109 y 116-117.

1975b. ¿Se puede hablar de transhumancia en la zona atacameña? Estudios Atacameños 3: 11-16.

1976a. Presentación. Estudios Atacameños 4: 7-10.

1976b. Apéndice sobre Tulor 4/Introducción al trabajo de la Dra. Myriam Tarragó. Estudios Atacameños 4: 33-36.

1976c. Discurso del R. P. Gustavo Le Paige s.j. en respuesta al ofrecimiento del título Doctor Honoris Causa. Anales de la Universidad del Norte: Homenaje al Dr. Gustavo Le Paige s.j. 10: 15-18.

1977. Recientes descubrimientos arqueológicos en la zona de San Pedro de Atacama. Estudios Atacameños 5: 109-124

1978. Presentación. Estudios Atacameños 6: 4.

LE PAIGE, G., y G. SARRACINO, 1973. Proyecto Tulan. Estudios Atacameños 1: 43-46.

LE PAIGE, G., y L. NÚÑEZ 1977. Editorial / Noticias. Estudios Atacameños 5:3-4 y 157-158.

MADRID DE COLIN, J., 1965. Entrevista al R. P. Gustavo Le Paige s.j. Boletín de la Sociedad Arqueológica de Santiago 3: 20-21.

MARTÍNEZ, G., 1983. Los dioses de los cerros en los Andes. Journal de la Societé des Américanistes 69: 85-115.

MARTÍNEZ, J. L., 2010. 'Somos resto de gentiles': El manejo del tiempo y la construcción de diferencias entre comunidades andinas. Estudios Atacameños 39: 57-70.

MENARD, A., 2006. Emergencia de la tercera columna en un texto de Manuel Manquilef. Anales de desclasificación I (2): 927-937

2010. Escrituras indígenas. Notas para la genealogía de un inverosímil. En II Simposio Internacional de Estéticas americanas, M. Alvarado (Ed.), pp. 253-267. Pontificia Universidad Católica de Chile, Instituto de Estética, Santiago. 
MENARD, A., y J. PAVEZ (Eds.), 2007. Mapuche y anglicanos. Vestigios fotográficos de la Misión Araucana de Kepe (1896-1908). Ocho Libros y Laboratorio de Desclasificación Comparada, Santiago de Chile.

2012. Raza y pudor en la pornología araucana. Anales de desclasificación 2 (1), en prensa.

MORALES, H., 1968-1969. Las ideas mágico-religiosas de los Atacamas. Boletín del Museo de Historia Natural 30: 129-145.

1997. Pastores transhumantes al fin del mundo. Un enfoque cultural de la tecnología en una comunidad andina de pastores. Memoria de título en Antropología, Universidad de Chile, Santiago.

2009. Etnopolitica en Atacama. Laberintos de la etnicidad atacameña. Ph.D. Dissertation, Freien Universtät Berlin.

MEGE, P., 2009. Viviendo en el mundo material. Fotografías de indígenas del desierto de Chile. Aisthesis. Revista chilena de investigaciones estéticas 46: 178-200.

MELCHER, G., 2004. El norte de Chile. Su gente, desierto y volcanes. Editorial Universitaria, Santiago de Chile.

MONDACA, C, W. SEGOVIA y E. SÁNCHEZ, 2011. Historia y sociedad del Departamento del Loa. Calama, una mirada desde los archivos. Ilustre Municipalidad de Calama, Calama.

MOSTNY, G. 1954. Peine, un pueblo atacameño. Facultad de Filosofía de la Universidad de Chile, Santiago.

(Ed.), 1964. Arqueología de Taltal. Epistolario de Augusto Capdeville con Max Uhle y otros arqueólogos e historiadores. Compilación, introducción y notas de G. Mostny, 2 tomos, Fondo Histórico y Bibliográfico José T. Medina, Santiago de Chile.

MUZZOPAPPA, E., 2003. Un pasado glorioso. Los mapuche en el discurso del ejército chileno. En Nación, Estado y Cultura en América Latina, A. Castillo y G. Rojo et al. (Eds.), Facultad de Filosofía y Humanidades Universidad de Chile, Santiago.

NÚÑEZ, L., 1980. Cazadores tempranos en Andes Meridionales. Evaluación cronológica de las industrias líticas del norte de Chile. Boletín de antropología americana 2: 87-120.

1983. Paleoindio y arcaico en Chile. Diversidad, secuencia y procesos. Ediciones Cuicuilco, México D.F.

1991. Cultura y conflicto en los oasis de San Pedro de Atacama. Editorial Universitaria, Santiago de Chile.

1993. Gustavo Le Paige S.J. Cronología de una misión, Ediciones Universitarias del Norte, Antofagasta.
OrellanA, M., 1963. Problema de la Arqueología de San Pedro de Atacama y sus alrededores. Anales de la Universidad del Norte: Congreso Internacional de Arqueología de San Pedro de Atacama (6-13 de enero 1963) 2: 29-42

1996. Historia de la Arqueología en Chile. Bravo y Allende editores, Santiago de Chile.

PALACIOS, N. 1986 [1904]. Raza Chilena. Editoral Antiyal, Santiago.

PALMIÉ, S., 2002. Genealogies of Moralities: the Afro-Cuban Nganga as Wage-Laborer, Slave, and Maroon. En Wizards and Scientists. Exploration in Afro-Cuban Modernity and Tradition, S. Palmié, pp. 159-200. Duke University Press, Durham.

2006. Thinking with Ngangas: Reflections on Embodiment and the Limits of "Objectively Necessary Appearances". Comparative Studies of Society and History 48 (4): 852-886.

PAVEZ, J., 2003. Mapuche ñi nütram chilkatun/ escribir la historia mapuche. Revista de Historia Indígena 7: 7-53.

2005. Advertencia al lector. Anales de desclasificación I (1): 11-15.

2007. Africanismes à Cuba (textes, images, classes). Tesis de doctorado, Ecole des Hautes Etudes en Sciences Sociales, Paris.

(Comp.), 2008. Cartas Mapuche. Siglo XIX. CoLibris/OchoLibros, Santiago de Chile.

2009. El retrato de los 'negros brujos': los archivos visuales de la antropología afrocubana (1900-1920). Aisthesis. Revista chilena de investigaciones estéticas 44:

REYES, S., 1969. Andanzas por el desierto de Atacama. Zig-Zag, Santiago de Chile.

RIVERA, F., 1994. Identidad en el laberinto: la búsqueda del sentido étnico en San Pedro de Atacama. Estudios Atacameños 11: 185-194.

RUDOLF, W. E., 1951. Chuquicamata Twenty Years Later. Geographical Review 41 (1): 88-113.

SALOMON, F., 2001. Una etnohistoria poco étnica. Nociones de lo autóctono en una comunidad campesina peruana. Desacatos 7: 65-84.

TÉLLEZ, I., 1944. Una raza militar. Imprenta La Sud-América, Santiago.

THAYER, W., 2005. El museo como campo expandido. Revista de la Academia 10: 287-305. 


\section{Jorge Pavez Ojeda}

TRIGGER, B., 1989. História do pensamento arqueológico. Odysseus, Rio de Janeiro.

UHLE, M., 1913. Los indios atacameños. Revista Chilena de Historiay Geografia 5 (9): 105-111.

1916. Sobre la estación paleolítica de Taltal. Una carta y un informe. Revista Chilena de Historia y Geografía 16 (20): 114-136.

1922. Fundamentos étnicos y arqueología de Arica y Tacna. Sociedad Ecuatoriana de Estudios Históricos, Quito.

VAN SCHUYLENBERGH, P., 1995. Découverte et vie des arts plastiques du Bassin du Congo dans la Belgique des années 1920-1930. En Rencontres artistiques beloique-Congo, 1920-1950, P. Schuylenbergh y F. Morimont (Eds.), pp. 1-62. Colección En- quêtes et documents d'histoire africaine 12, Centre d'Histoire de l'Afrique, Louvain La Neuve.

VEZUB, J., 2005. Historiar las prácticas etnográficas. Tomás Harrington y la morfología de la cultura en la Patagonia septentrional hacia 1940. En Sociedades en movimiento. Los pueblos indígenas de América Latina en el siglo XIX, A. Escobar, R. Mandrini y S. Ortelli (Eds.) pp. 175-187. Instituto de Estudios Histórico Sociales, Tandil.

2009. Henry de La Vaulx en Patagonia (1896-1897): la historicidad escindida de la antropología colonial y la captura de corpus y cuerpos, Nuevo Mundo Mundos Nuevos [En línea]. URL: http://nuevomundo.revues.org/57810. Consultado el o9 novembre 2011.

VIDAL, H., 1989. Mitología militar chilena, surrealismo del superego. Institute for the Study of Ideology and Literature, Minneapolis. 